Document downloaded from:

http://hdl.handle.net/10251/100064

This paper must be cited as:

Vayá Pérez, I.; Bueno Alejo, CJ.; Jiménez Molero, MC.; Miranda Alonso, MÁ. (2006). Use of triplet excited states for the study of drug binding to human and bovine serum albumins. ChemMedChem. 1(9):1015-1020. doi:10.1002/cmdc.200600061

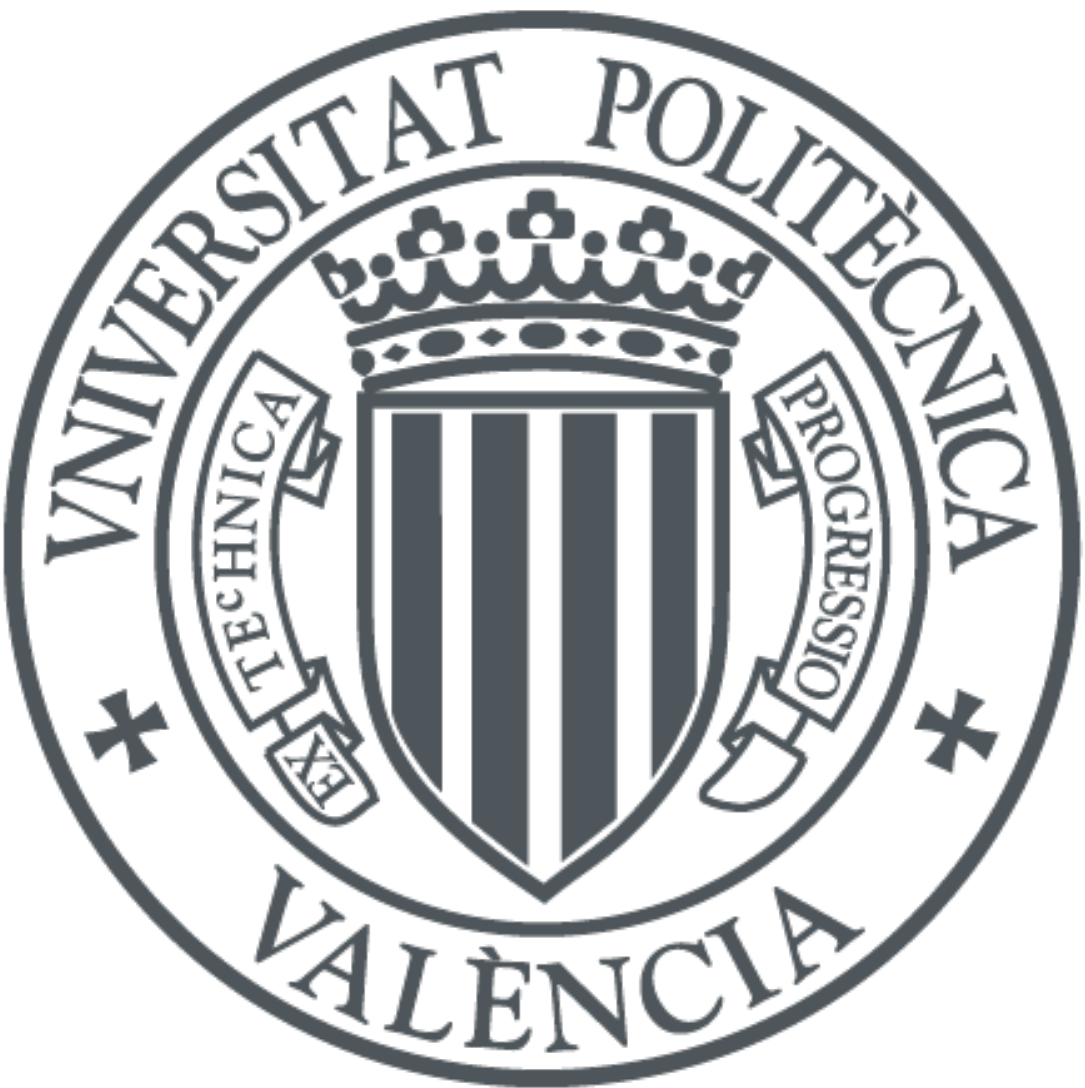

The final publication is available at

https://doi.org/10.1002/cmdc.200600061

Copyright John Wiley \& Sons

Additional Information 


\title{
Use of Triplet Excited States for the Study of Drug Binding to Human and Bovine Serum Albumins
}

Ignacio Vayá, Carlos J. Bueno, M. Consuelo Jiménez* and Miguel A.

Miranda*

Departamento de Química-Instituto de Tecnología Química UPV-CSIC, Universidad Politécnica de Valencia, Camino de Vera s/n, E-46022 Valencia, Spain.

Keywords: Flurbiprofen, Serum Albumin, Binding Site, Laser Flash Photolysis.

\begin{abstract}
The triplet excited states of (S)- and (R)-flurbiprofen (FBP) have been used as reporters for the microenvironments experienced within the binding sites of human and bovine serum albumins. Regression analysis of triplet decay provides valuable information on the degree of protection of these excited states from attack by a second FBP molecule, oxygen or other reagents. The multiexponential fitting of these decays can be satisfactorily correlated with the distribution of the drug among the two binding sites and its presence as the non-complexed form in the bulk solution. This assignment has been confirmed by using (S)-ibuprofen or caproic acid as selective site-II replacement probes. Triplet lifetimes and site occupancy are sensitive to the type of serum albumin employed (human vs. bovine). Finally, a low stereodifferentiation has been found in the binding behaviour of $(S)$ - and $(R)$-FBP.
\end{abstract}




\section{Introduction}

Serum albumins (SA) are very abundant proteins in blood and plasma. One of their most important physiological roles is to carry a variety of agents (such as fatty acids, drugs or metabolites) in the bloodstream to achieve a selective delivery to specific targets. ${ }^{1,2}$ Binding of drugs to SA in biological systems is a key process, as it is relevant to modulate a number of properties, including increased solubility in plasma, decreased toxicity, protection against oxidation, prolongation of the in vivo half-life, etc.

Human (HSA) and bovine (BSA) serum albumins have been used as model proteins for diverse studies. ${ }^{3,4}$ They have a well known primary structure and a similar folding. Binding of small molecules (i.e. drugs or fatty acids) to HSA and BSA has been studied for years through different techniques, in order to understand the functions of this unique type of carrier and to disclose the structural basis for designing new therapeutic agents. ${ }^{5,6}$

Thus, it is known that HSA is synthesised and secreted by liver cells. Its primary structure consists of a single chain of 585 amino acid residues containing 17 disulfide bridges, one tryptophan (Trp) and one free cysteine; the secondary structure is formed by $67 \%$ of $\alpha$ helix of six turns, while the three-dimensional structure can be described in terms of three domains, each of them constituted in turn by two subdomains. ${ }^{7}$ Usually, drugs bind primarily to high-affinity sites, with typical association constants in the range of $10^{4}-10^{6} \mathrm{M}^{-1}$. In addition to the primary sites, lower affinity sites are often populated. The pioneering work of Sudlow and coworkers, based on the displacement of fluorescence probes, revealed that a great number of drugs bind with high affinity to one or two sites, called site I (warfarin binding site) and site II (indole-benzodiazepine binding site). ${ }^{8}$ 
Likewise, BSA is among the most studied and currently used proteins in biochemical research; BSA and HSA present 76\% sequence identity, but the former contains two Trp residues, instead of one. In general, the structural differences observed between both albumins are mainly of conservative nature; e. g. hydrophobic amino acids are replaced by other hydrophobic amino acids rather than by polar ones.

Many studies on the drug-protein binding process have used BSA as model, due to its similarity to HSA. ${ }^{9,10}$ However, the binding strength of several ligands (naproxen, carprofen and ibuprofen, among others) to the bovine protein has proven to be different from that found for the human protein. ${ }^{11-21}$ Therefore, the development of new tools for the investigation of drug-protein interactions, as well as for the comparison between binding of drugs to HSA and BSA, seems to be important in order to integrate the existing knowledge.

In the past, a number of techniques (equilibrium dialysis/HPLC, ultrafiltration, spectrophotometry, fluorometry, calorimetry, circular dichroism, capillary electrophoresis, NMR diffusion measurements, etc) have been used for drug-protein binding studies. ${ }^{22-31}$ Each of them presents advantages and limitations; the latter are mainly related to sensitivity, interferences, diffusion problems or lack of reproducibility arising from a complicated workup.

A possible alternative to these methodologies could be based on the detection of transients by laser flash photolysis (LFP). Thus, triplet excited states have demonstrated to be extremely sensitive to the experienced microenvironment, since their dynamic properties can be strongly medium-dependent. ${ }^{32}$ Hence, these transient species can be regarded as potential reporters for the binding of drugs to serum albumins. From the multiexponential decay kinetics, it could even be possible to analyse the drug distribution among the bulk solution and the different protein binding sites. More 
interestingly, triplet lifetime measurements would depend on the nature of the drugHSA complexes, such as strength of the interaction, conformational restrictions, stereochemical requirements, inhibition of self-quenching or triplet-triplet annihilation, protection from attack by oxygen or other reagents, etc.

In a recent preliminary communication, we have reported on the suitability of the triplet excited states of (R)- and (S)-flurbiprofen methyl ester (FBPMe) to obtain relevant information about the binding of this compound to HSA. ${ }^{33}$ The triplet lifetimes $\left(\tau_{\mathrm{T}}\right)$ of (R)- and (S)-FBPMe were dramatically enhanced within the HSA microenvironment. Moreover, two different $\tau_{\mathrm{T}}$ values were found for protein-included FBPMe, associated with the presence of the drug in two different binding sites. Based on these values, the populations of the two binding sites at different [FBPMe]/HSA] ratios were determined by regression analysis of the triplet decay traces.

In our previous work, FPBMe was used for convenience, as its hydrophobic character favours inclusion within the protein. However, the analogous information obtained from the triplet state of flurbiprofen (FBP, the free carboxilic acid) which is the form usually prescribed to patients, would be more relevant for pharmacokinetic purposes.

As shown in Chart I, the non-steroidal anti-inflammatory drug FBP is a 2arylpropionic acid. It is prescribed for the relief of mild to moderately severe pain accompanied by inflammation (rheumatoid arthritis, osteoarthritis, tendinitis, bursitis) and also for ophthalmic disorders. Although the pharmacological effect of FBP is mainly due to the (S)-enantiomer, it is usually commercialised as a racemic mixture. ${ }^{34}$ Recently, it has been described that FBP inhibits selectively secretion of $A \beta 42$, the most toxic component of the senile plaques present in the brain of Alzheimer patients. ${ }^{35}$ Concerning the binding to HSA, it has been previously established that FBP binds 
preferentially to site II, but the lower affinity binding site I is also populated to some extent. $^{36,37}$

In the present work, we have undertaken a systematic LFP study on both (S)and (R)-FBP in the presence of different amounts of HSA or BSA, using the wellcharacterised triplet-triplet absorption of FBP as reporter. ${ }^{38}$ It will be shown that the most significant differences between both albumins are related to dynamic ranges found for the FBP excited state lifetimes within the proteins and to the relative occupancy of the two binding sites.

\section{Results and Discussion}

\section{(S)-Flurbiprofen/SA systems.}

The behaviour of the (S)-enantiomer of FBP was examined first. For the studies in the presence of HSA, a battery of aqueous solutions containing (S)-FBP and HSA (molar ratios between 10:1 and 0.3:1) were prepared in neutral buffer (0.01 M PBS) and submitted to LFP. In all cases, the transient absorption spectra obtained after laser excitation $\left(\lambda_{\text {exc }}=266 \mathrm{~nm}\right)$ displayed a maximum at $360 \mathrm{~nm}$, assigned to the first triplet

excited state. $^{38}$ Remarkably, while the decay at $360 \mathrm{~nm}$ in the absence of protein followed a first order exponential law with a lifetime of $1.5 \mu$ s, in the presence of HSA it required multiexponential fitting and occurred at longer timescales (Figure 1).

Thus, when the $[(S)-F B P] /[H S A]$ ratio was between $0.7: 1$ and $0.5: 1$, a double exponential decay was observed with lifetimes of 11.2 and $35.9 \mu$ s. The negligible contribution of the $1.5 \mu$ s component indicated the absence of free $(S)$-FBP in solution under these conditions. The fact that two different $\tau_{\mathrm{T}}$ values were obtained in the presence of HSA correlates well with the existence of two different types of 
microenvironments (i.e., two different binding sites) in the protein. It is worth mentioning that protein-bound (S)-FBP has considerably longer lifetimes (up to 24 times) than the non-complexed form. This can be attributed to a slower deactivation of the excited states inside the HSA binding sites, where an exceptional microenvironment protecting the triplet excited state from attack by a second (S)-FBP molecule, oxygen or other reagents is provided. In order to check this hypothesis, parallel experiments were performed in $\mathrm{N}_{2-}$ and $\mathrm{O}_{2}$-purged solutions of (S)-FBP in PBS, both in the absence and in the presence of HSA. As a matter of fact, the triplet decay rate increased with increasing oxygen concentration. The decay traces are shown in the supporting information (see Figures S5 and S6, pp. S11 and S12), while the rate constants are given in Table 1. Clearly, the quenching process occurs within the protein microenvironment much slower than in the bulk solution. Moreover, protection for oxygen attack seems to be more effective within the high affinity Site II.

At higher $[(S)-F B P] /[H S A]$ ratios (from 0.8:1 to 10:1), three lifetime values (1.5, 11.2 and $35.9 \mu \mathrm{s}$ ) were necessary to obtain a good fitting of the decay signal (also shown in Figure 1). This can be clearly associated with the presence of the two FBPHSA species $\left(\tau_{\mathrm{T}}=11.2\right.$ and $\left.35.9 \mu \mathrm{s}\right)$, in addition to free $(S)$-FBP $\left(\tau_{\mathrm{T}}=1.5 \mu \mathrm{s}\right)$.

Regression analysis of the decay curves for [(S)-FBP]/[HSA] ratios from 10:1 to 0.8:1 allowed to obtain the values of the $A_{1}, A_{2}$ and $A_{3}$ coefficients (corresponding to the three components with different lifetimes, correlated with free, site I-bound and site II-bound FBP). Based on the known fact that the high affinity site of FBP is site II, ${ }^{36,37}$ the major component under non-saturating conditions (associated with the longest $\tau_{\mathrm{T}}$ ) was assigned to FBP within site II; consequently, the minor component (with $\tau_{\mathrm{T}}=11.2$ $\mu$ s) was assigned to site I-bound FBP. Moreover, in order to obtain independent evidence supporting this assignment, additional LFP experiments were performed in the 
presence of (S)-ibuprofen ((S)-IBP) and capric acid (CA), whose affinity for binding in site II is known to be very high..$^{39,40}$ In good agreement with the initial assumptions, addition of IBP or CA to the (S)-FBP/HSA solutions resulted in a reduced contribution of the longest lifetime component (site II-bound FBP), with a concomitant enhancement of the components assigned to free and site I-bound FBP. The percentages of free, site Iand site II-bound FBP in the presence of HSA (and eventually (S)-IBP or CA) are shown in Table 2.

In order to investigate the behaviour of (S)-FBP in the bovine protein, parallel experiments were carried out in the presence of increasing amounts of BSA. Thus, PBS solutions of (S)-FBP and BSA (molar ratio in the range from 10:1 to 0.3:1) were submitted to LFP. Again, two components with $\tau_{\mathrm{T}}=10.8$ and $86.5 \mu$ s were obtained for the triplet decay $(\lambda=360 \mathrm{~nm})$ inside the protein. This is shown in Figure 2.

Regression analysis of the decay curves for [(S)-FBP]/[BSA] ratios from 10:1 to 1:1 (where some free drug is present) allowed us to obtain the values of the $A_{1}, A_{2}$ and $\mathrm{A}_{3}$ coefficients. The major component under non-saturating conditions $\left(\tau_{\mathrm{T}}=86.5 \mu \mathrm{s}\right)$ was assigned to (S)-FBP in the high affinity binding site (site II), while the minor component (with $\tau_{\mathrm{T}}=10.8 \mu \mathrm{s}$ ) was attributed to (S)-FBP within site I. Experiments in the presence of (S)-IBP or CA supported this assumption. Relevant data are shown in Table 2.

It is remarkable that the triplet excited state of site II-bound (S)-FBP lived much longer (2.4 times) within BSA than within HSA; however, no significant differences were found in the corresponding values of site I-bound (S)-FBP. The results indicate that the triplet excited state of (S)-FBP is more protected for deactivation (due to attack by a second (S)-FBP molecule, oxygen, other reagents, etc.) within the microenvironment provided by site II in BSA; besides, binding to this site appears to be 
the strongest one, as pointed by the fact that replacement of $(S)$-FBP here is more difficult than in the other SA microenviroments. Accordingly, triplet quenching by oxygen was slower inside the protein, specially in Site II (see Table 1 and supporting information, Figures S5 and S7, pp. S11 and S13).

Concerning the site occupancy, as estimated from A coefficients of the regression analysis curves, the main differences between the behaviour of the two proteins were found at low $[(S)-\mathrm{FBP}] /[\mathrm{SA}]$ ratios. This is shown in Figure 3; further plots illustrating the binding behaviour can be found in the supporting information, Figures S10 and S11, pp. S16 and S17.

\section{(R)- Flurbiprofen/SA systems}

As stated above, the pharmacological effect or flurbiprofen is mainly attributed to the (S)-enantiomer, although the drug is commercialised for therapeutic purposes as a racemic mixture. In order to check whether significant differences in the binding behaviour were observable for the two enantiomers, a similar study was performed on (R)-FBP in the presence of both serum albumins.

As expected, in PBS solution the transient absorption spectra and the triplet lifetimes of the two FBP enantiomers did not differ from each other. When included within HSA, two components with $\tau_{\mathrm{T}} 10.2 \mu$ s and $39.0 \mu$ s were found for $(R)$-FBP. These values were only slightly different from those obtained for (S)-FBP, indicating a little stereodifferentiation in the HSA binding process. Representative decays of the signal monitored at $360 \mathrm{~nm}$ are shown in Figure 4.

As in the case of (S)-FBP, LFP experiments for the (R)-FBP/HSA systems in the presence of (S)-IBP or CA supported the initial site I and site II assignments. Thus, addition of (S)-IBP or CP to the (R)-FBP/HSA solutions resulted in dramatic reduction of the amount of site II-bound (R)-FBP (up to 5.8 times lower), with a parallel 
enhancement of the free and site I-bound species (significant data are shown in Table 2).

Finally, similar studies were carried out for $(R)$-FBP in the presence of the bovine protein. From the LFP kinetic decays of (R)-FBP/BSA solutions (Figure 5), two values of $\tau_{\mathrm{T}}$ (6.6 and $\left.58.6 \mu \mathrm{s}\right)$ were obtained and attributed to site I-bound and site IIbound (R)-FBP, respectively. Oxygen quenching experiments led to results similar to those obtained with (S)-FBP (Table 1 and supporting information, Figures S8 and S9, pp. S14 and S15).

On the other hand, addition of (S)-IBP or CA to the (R)-FBP/BSA solutions resulted in a redistribution of the bound drug (Table 2), which partially moved from site II to site I. Interestingly, no detectable amounts of free drug were found under these conditions.

The site occupancy, estimated from A coefficients of the regression analysis curves, are shown in Figure 6. The main differences between the behaviour of the two proteins were found again at low $[(S)-\mathrm{FBP}] /[\mathrm{SA}]$ ratios.

A comparison between the decays monitored at $360 \mathrm{~nm}$ for (S)-FBP/HSA (S)FBP/BSA, (R)-FBP/HSA and (R)-FBP/BSA is shown in Figure 7. It clearly shows that the binding behaviour of FBP is different in the two proteins. Besides, some stereodifferentiation occurs in BSA, while no significant differences between the two FBP enantiomers were observed whithin HSA.

\section{Conclusions}

The results obtained in the present work confirm that the triplet drug excited states can be used as reporters for the microenvironments experienced within the binding sites of transport proteins. Regression analysis of triplet decays can provide 
valuable information on the degree of protection of these excited states from attack by a second drug molecule, oxygen or other reagents. The multiexponential fitting of these decays can be satisfactorily correlated with the distribution of the drug among the two binding sites and its presence as the non-complexed form in the bulk solution. This assignment has been confirmed by using selective site-II replacement probes. Both triplet lifetimes and site occupancy are sensitive to the type of serum albumin employed (human vs. bovine). Finally, a lower stereodifferentiation has been found in the binding behaviour of (S)- and (R)-FBP than in the case of their methyl esters.

\section{Experimental Section}

\section{Materials}

HSA and BSA were purchased from Sigma. (S)- and (R)-FBP were obtained from Aldrich.

\section{Absorption spectra}

The absorbance of the solutions was measured in a Perkin Elmer Lambda 35 UV/Vis Spectrometer.

\section{Laser flash photolysis experiments.}

Laser flash photolysis experiments were performed by using a Q-switched Nd:YAG laser (Quantel Brilliant, $266 \mathrm{~nm}, 14 \mathrm{~mJ}$ per pulse, $5 \mathrm{~ns}$ fwhm) coupled to a mLFP-111 Luzchem miniaturised equipment. All transient spectra were recorded employing $10 \times 10 \mathrm{~mm}^{2}$ quartz cells with $4 \mathrm{~mL}$ capacity. The absorbance of FBP was found to be $c a .0 .2$ at the laser wavelength, corresponding to a concentration of $2.5 \cdot 10^{-5}$ M; concentration of SA was determined using the molar absorption coefficients at 280 
$\mathrm{nm}$ of $35700 \mathrm{M}^{-1} \mathrm{~cm}^{-1}$ for HSA and $44720 \mathrm{M}^{-1} \mathrm{~cm}^{-1}$ for BSA. All the experiments were carried out in PBS $(\mathrm{pH}=7.4,0.01 \mathrm{M})$ at room temperature $\left(22{ }^{\circ} \mathrm{C}\right)$ and under air atmosphere.

For the studies in the presence of SA, a battery of aqueous solutions containing $(S)$ - or $(R)$-FBP and SA (molar ratios between 10:1 and 0.3:1) were prepared in neutral buffer (0.01 M PBS) and stored during $15 \mathrm{~h}$ at $4{ }^{\circ} \mathrm{C}$ to ensure a complete equilibrium between the drug and the protein. As an example, the experimental procedure to prepare a solution containing FBP and SA in 10:1 molar ratio is briefly described: to $20 \mathrm{~mL}$ of a $2.5 \cdot 10^{-5} \mathrm{M}$ solution of (S)- or (R)-FBP in PBS, $25 \mu \mathrm{L}$ of SA $2 \cdot 10^{-3} \mathrm{M}$ in PBS were added. The resulting solution ( $4 \mathrm{~mL}$ ) was placed in a quartz cuvette and submitted to LFP (10 shots for monitoring at $360 \mathrm{~nm}$ ). To obtain an accurate decay trace, this experiment was repeated at least three times with fresh sample; triplet lifetimes and fittings of the decay traces were coincident within the experimental error margins. To obtain the transient absorption spectra from 700 to $290 \mathrm{~nm}$, fresh sample (drug and protein concentración $2.510^{-5} \mathrm{M}$ ) was submitted to LFP in a regular interval of $10 \mathrm{~nm}$ (10 shots per wavelength) measuring a total of 41 decays for each spectrum acquisition.

\section{Acknowledgements}

Financial support from the MCYT (CTQ2004-03811) and the Generalitat Valenciana (GV06/099) is gratefully acknowledged. I. V. thanks "Ministerio de Educación y Ciencia” for a fellowship. 


\section{References}

[1] T. Peters, All about albumins: Biochemistry, Genetics and Medical Applications, Academic Press, 1995, San Diego.

[2] D. C. Carter, J. X. Ho in Advances in Protein Chemistry, Vol.45, Academic Press, New York, 1994, pp 152-203.

[3] B. X. Li, Z. J. Zhang, L. X. Zhao, Anal. Chim. Acta 2002, 468, 65.

[4] T. C. Kwing, Clin. Chim. Acta 1985, 151, 193.

[5] C. K. Svenson, M. N. Woodruff, J. G. Baxter, D. Lalka, Clin. Pharmacokinet. 1985, $11,450$.

[6] T. Peters, Advances in Protein Chemistry, Vol. 37, Academic Press, New York, 1985.

[7] X. M. He, D. C. Carter, Nature, 1992, 358, 209.

[8] G. Sudlow, D. J. Birkett, D. N. Wade, Mol. Pharmacol. 1975, 11, 824.

[9] P. Sun, A. Hoops, R. A. Hartwick, J. Chrom. B 1994, 661, 335.

[10] J. B. Whitlam, M. J. Crooks, K. F. Brown, P. V. Pedersen, Biochemical Pharmacol. 1979, 28, 675.

[11] S. Wei, L. Zhao, X. Cheng, J.-M. Lin, Analytica Chim. Acta 2005, 545, 65.

[12] H. Kphita, Y. Matsushita, I. Moriguchi, Chem. Pharm. Bull. 1994, 42, 937.

[13] E. L. Gelamo, C. H. T. P. Silva, H. Imasato, M. Tabak, Biochim. Biophsys. Acta 2002, 1594, 84.

[14] E. L. Relamo, M. Tabak, Spectrochim. Acta Part A 2000, 56A, 2255.

[15] F. Fleury, I. Kudelina, I. Nabiew, FEBS Lett. 1997, 406, 151.

[16] K. R. Kuchimanchi, M. S. Ahmed, T. P. Johnston, A. K. Mitra, J. Pharm. Sci. 2001, 90, 659 . 
[17] D. Silva, C. Cortez, S. R. W. Louro, Spectrochim. Acta, Part A 2004, 60A, 1215.

[18] G. N. Valsami, M. Panayotis, M. A. Koupparis, Pharm. Res. 1991, 8, 888.

[17] G. Manzini, V. Crescenci, Biophys. Chem. 1979, 10, 397.

[19] W. E. Muller, U. Wollert Biochemical Parmacology 1976, 25, 141.

[20] K. Kitamura, M. Kume, M. Yamamoto, S. Takegami, T. Kitade, J. Pham. Biomed. Anal. 2004, 36, 411.

[21] A. Sulkowska, J. Mol. Struct. 2002, 227.

[22] Z. Jia, T. Ramstad, M. Zhong, J. Pharm. Biomed. Anal. 2002, 405, 413;

[23] L. H. Lucas, K. E.Price, C. K. Larive, J. Am. Chem. Soc. 2004, 126, 14258.

[24] R. Zini, D. Morin, P. Jouenne, J. P. Tillement, Life Sci. 1988, 43, 2103.

[25] J. Barne, J. M. Chamouard, G. Houin, J. P. Tillement, Clin. Chem. 1985, 31, 60.

[26] W. F. Bowers, S. Fulton, J. Thompson, Clin. Pharmacokinet. 1984, 9, 49.

[27] H. Aki, M. Yamamoto, J. Pharm. Pharmacol. 1989, 41, 674.

[28] H. H. Parikh, K. McElwaine, V. Balasubramanian, W. Leung, D. Won, M. E. Morris, M. Ramanathan, Pharm. Res. 2000, 17, 632.

[29] A. Frostell-Karlsson, A. Remaeus, H. Roos, K. Andersson, P. Borg, M. Hämäläinen, R. Karlsson, J. Med. Chem. 2000, 43, 1986.

[30] A. Shibukawa, Y. Kuroda, T. Nakagawa, J. Pharm. Biomed. Anal. 1999, 18, 1047.

[31] Y. H. Chu, L. Z. Avila, H. A. Biebuyck, G. M. Whitesides, J. Med. Chem. 1992, 35, 2915.

[32] Bohne, C.; Barra, M.; Boch, R.; Abuin, E. B.; Scaiano, J. C. J. Photochem. Photobiol. A: Chem, 1992, 65, 249.

[33] M. C. Jiménez, M. A. Miranda, I. Vayá, J. Am. Chem. Soc. 2005, 127, 10134.

[34] A.M. Evans, J. Clin. Pharmacol. 1996, 36, 7S. 
[35] I Peretto, S. Radaelli, C. Parini, M. Zandi, L. F. Raveglia, G. Dondio, L. Fontanella, P. Misiano, C. Bigogno, A. Rizzi, B. Riccardi, M. Biscaioli; S. Marchetti, P. Puccini, S. Catinella, I. Rondelli, V. Cenacchi,P. T. Bolzoni, P. Caruso, G. Villetti, F. Facchinetti, E. Del Giudice, N. Moretto, B. P. Imbimbo, J. Med. Chem. 2005, 48, 5705. [36] J. Ostergaard, C. Schou, C. Larsen, N. H. H. Heegaard, Anal. Chem. 2003, 75, 207. [37] L. Deschamps-Labat, F. Péhourcq, M. Jagou, B. Bannwarth, J. Pharm. Biomed. Anal. 1997, 16, 223.

[38] M. C. Jiménez, M. A. Miranda, R. Tormos, I. Vayá, Photochem. Photobiol. Sci. 2004, 3, 1038.

[39] T. Itoh, Y. Saura, Y. Tsuda, H. Yamada, Chirality 1997, 9, 643.

[40] G. Menke, W. Wörner, W. Kratzer, N. Rietbrock, Arch. Pharmacol. 1989, 339, 42. 


\section{Figure Legends}

Figure 1. Laser flash photolysis $\left(\lambda_{\text {exc }}=266 \mathrm{~nm}\right)$ of $(S)$-FBP and $(S)$-FBP/HSA at different molar ratios. Normalised decays monitored at $360 \mathrm{~nm}$. The concentration of (S)-FBP was $2.5 \cdot 10^{-5} \mathrm{M}$ in all cases.

Figure 2. Laser flash photolysis $\left(\lambda_{\text {exc }}=266 \mathrm{~nm}\right)$ of $(S)$-FBP and $(S)$-FBP/BSA at different molar ratios. Normalised decays monitored at $360 \mathrm{~nm}$. The concentration of (S)-FBP was $2.5 \cdot 10^{-5} \mathrm{M}$ in all cases.

Figure 3. A. Percentage of free, site I- and site II-bound (S)-FBP in the presence of HSA at different $[(S)$-FBP]/[HSA $]$ ratios. B. Percentage of free, site I- and site II-bound (S)-FBP in the presence of BSA at different $[(S)$-FBP $] /[\mathrm{BSA}]$ ratios.

Figure 4. Laser flash photolysis $\left(\lambda_{\mathrm{exc}}=266 \mathrm{~nm}\right)$ of $(R)-\mathrm{FBP}$ and $(R)-\mathrm{FBP} / \mathrm{HSA}$ at different molar ratios. Normalised decays monitored at $360 \mathrm{~nm}$. The concentration of (R)-FBP was $2.5 \cdot 10^{-5} \mathrm{M}$ in all cases.

Figure 5. Laser flash photolysis $\left(\lambda_{\text {exc }}=266 \mathrm{~nm}\right)$ of $(R)$-FBP and $(R)-\mathrm{FBP} / \mathrm{BSA}$ at different molar ratios. Normalised decays monitored at $360 \mathrm{~nm}$. The concentration of (R)-FBP was $2.5 \cdot 10^{-5} \mathrm{M}$ in all cases.

Figure 6. A. Percentage of free, site I- and site II-bound (R)-FBP in the presence of HSA at different $[(R)$-FBP $] /[\mathrm{HSA}]$ ratios. B. Percentage of free, site I- and site II-bound $(R)$-FBP in the presence of BSA at different $[(R)-F B P] /[B S A]$ ratios.

Figure 7. Decays monitored at $360 \mathrm{~nm}$ obtained upon laser flash photolysis $\left(\lambda_{\text {exc }}=266\right.$ nm 0.01 M PBS, air) of (S)-FBP/BSA, (R)-FBP/BSA, (S)-FBP/HSA and (R)-FBP/HSA and. The [drug]/[SA] ratio was always 0.7:1. 


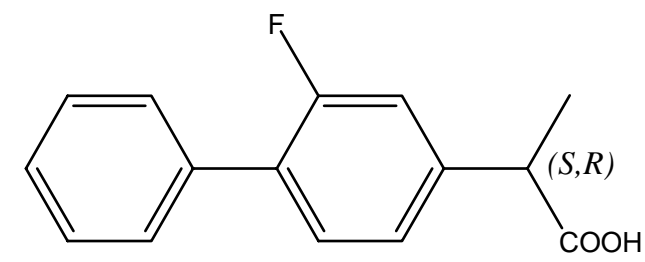

Chart 1 


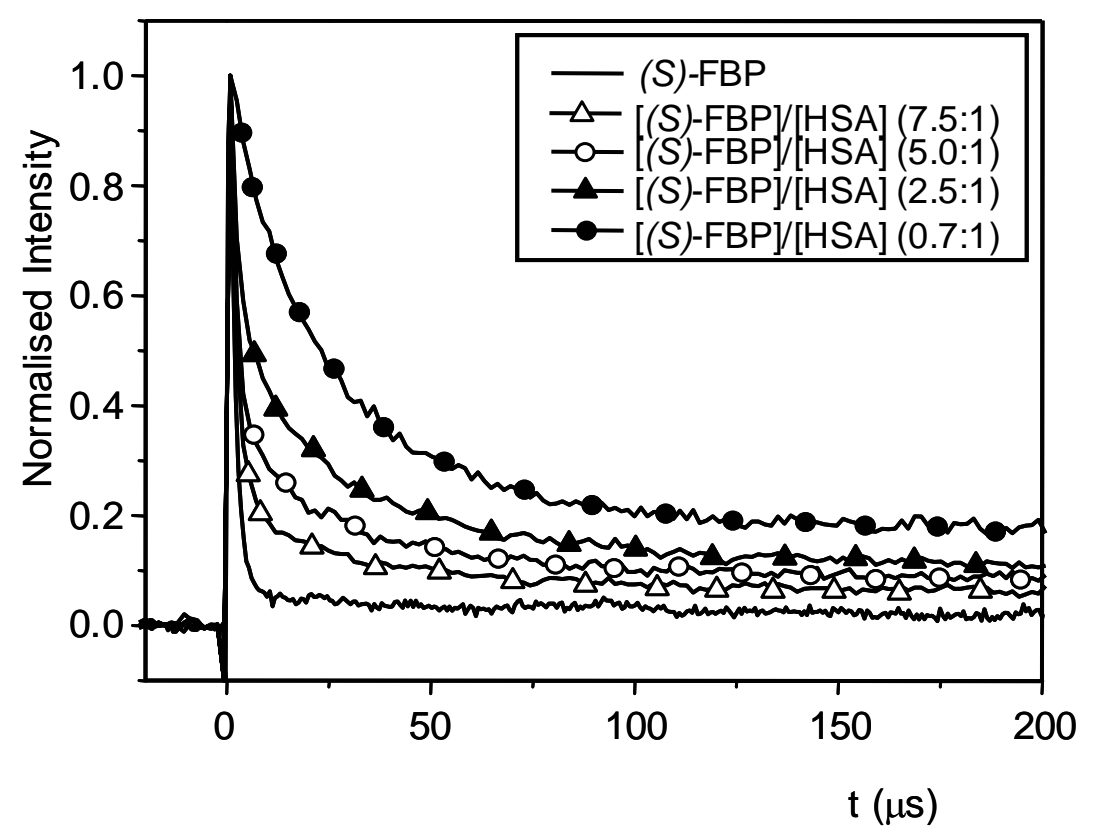

Figure 1 


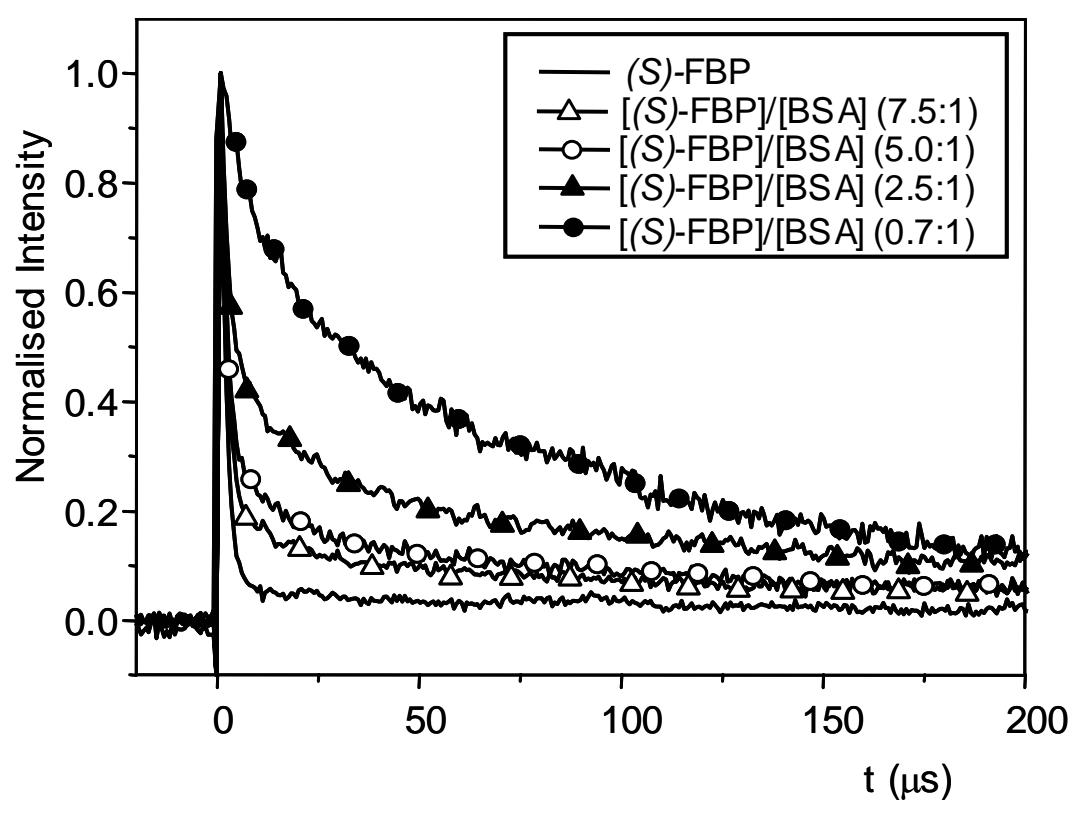

Figure 2 

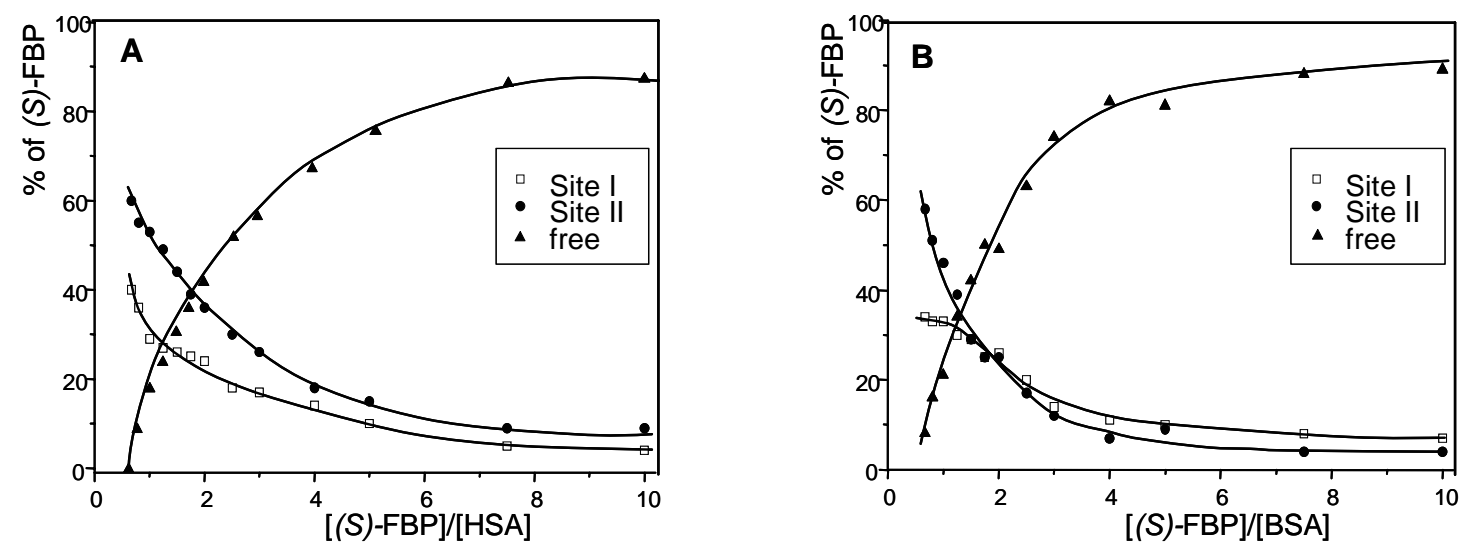

Figure 3 


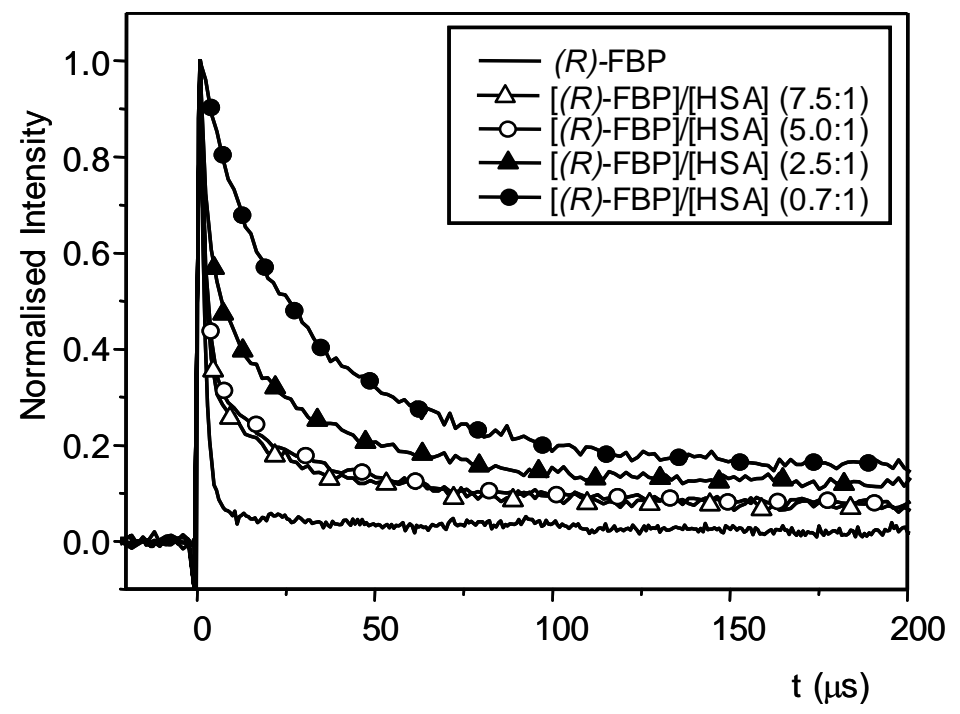

Figure 4 


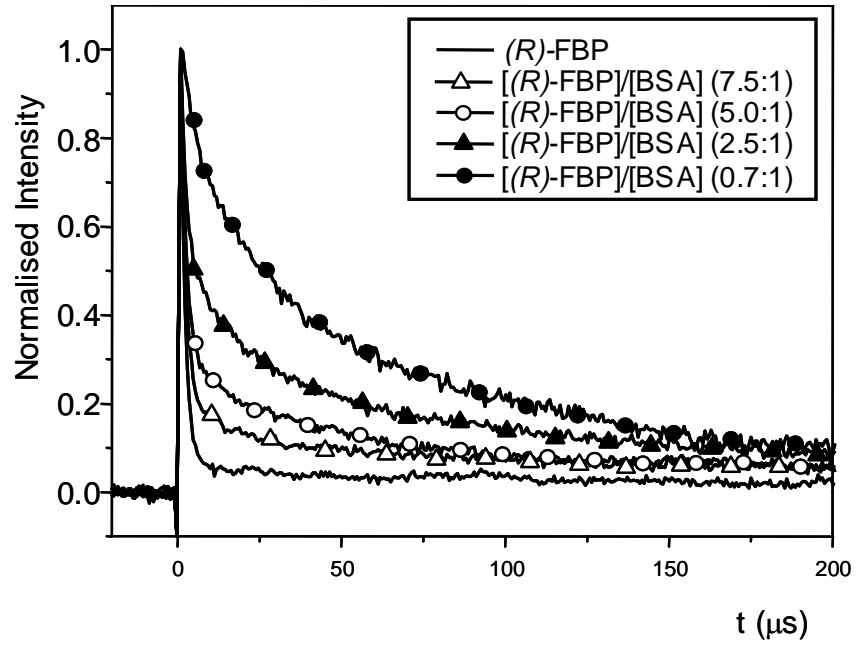

Figure 5 

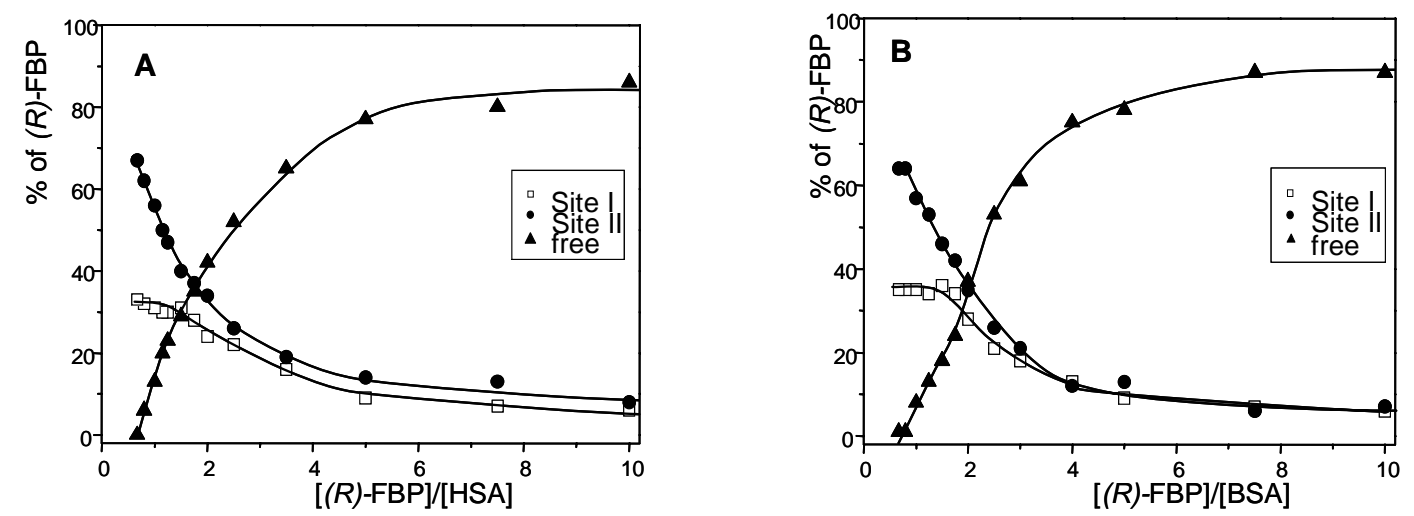

Figure 6 


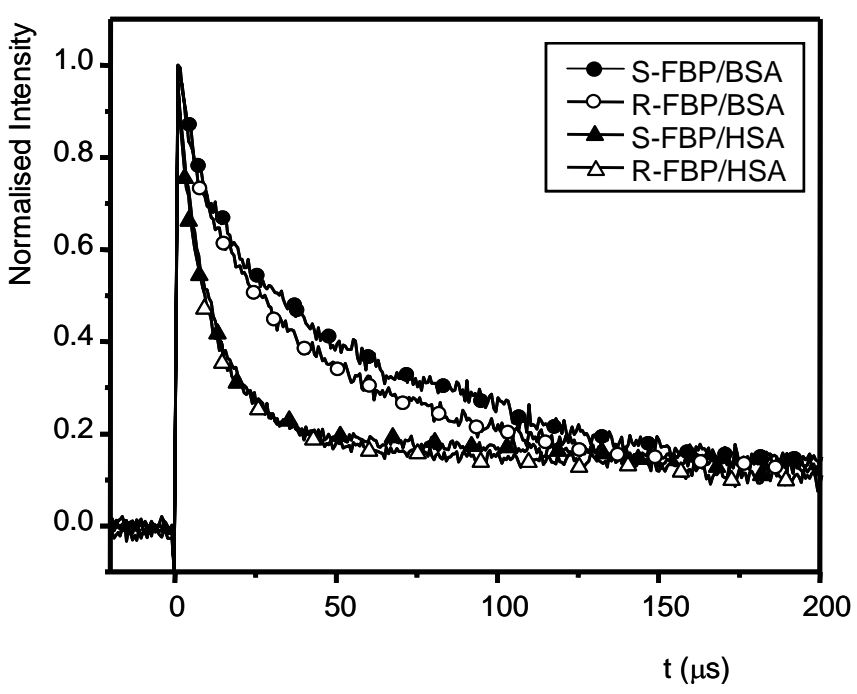

Figure 7 
Table 1. Rate constants of triplet quenching by oxygen for FBP free, in site I and site II.

\begin{tabular}{ccc}
\hline & Microenvironment & $\mathrm{k}_{\mathrm{q}}\left(\mathrm{O}_{2}\right) \mathrm{M}^{-1} \mathrm{~s}^{-1}$ \\
\hline$[(\mathrm{S})-\mathrm{FBP}]$ & Solution & $1.0 \cdot 10^{9}$ \\
{$[(S)-\mathrm{FBP}] /[\mathrm{HSA}]^{\mathrm{a}}$} & Site I & $2.1 \cdot 10^{8}$ \\
& Site II & $9.1 \cdot 10^{7}$ \\
{$[(R)-\mathrm{FBP}] /[\mathrm{HSA}]^{\mathrm{a}}$} & Site I & $2.0 \cdot 10^{8}$ \\
& Site II & $3.9 \cdot 10^{7}$ \\
{$[(S)-\mathrm{FBP}] /[\mathrm{BSA}]^{\mathrm{a}}$} & Site I & $4.0 \cdot 10^{8}$ \\
& Site II & $3.4 \cdot 10^{7}$ \\
{$[(R)-\mathrm{FBP}] /[\mathrm{BSA}]^{\mathrm{a}}$} & Site I & $1.9 \cdot 10^{8}$ \\
& Site II & $4.6 \cdot 10^{7}$ \\
\hline
\end{tabular}


Table 2. Percentage of free, site I- and site II-bound (S)-FBP or (R)-FBP under different conditions.

$\begin{array}{ccc}\text { Free } & \text { Site I-bound } & \text { Site II-bound } \\ (S) \text {-FBP }(\%) & (S) \text {-FBP (\%) } & (S) \text {-FBP (\%) }\end{array}$

\begin{tabular}{|c|c|c|c|}
\hline$[(S)-\mathrm{FBP}]$ & 100 & - & - \\
\hline$[(S)-F B P] /[H S A]^{\mathrm{a}}$ & 0 & 40 & 60 \\
\hline$[(S)-F B P] /[H S A] /[(S)-I B P]^{b}$ & 27 & 65 & 8 \\
\hline$[(\mathrm{S})-\mathrm{FBP}] /[\mathrm{HSA}] /[\mathrm{CA}]^{\mathrm{b}}$ & 29 & 59 & 12 \\
\hline$[(S)-\mathrm{FBP}] /[\mathrm{BSA}]^{\mathrm{a}}$ & 0 & 39 & 61 \\
\hline$[(S)-\mathrm{FBP}] /[\mathrm{BSA}] /[(S)-\mathrm{IBP}]^{\mathrm{b}}$ & 8 & 58 & 34 \\
\hline$[(S)-F B P] /[\mathrm{BSA}] /[\mathrm{CA}]^{\mathrm{b}}$ & 5 & 57 & 38 \\
\hline$[(R)-\mathrm{FBP}] /[\mathrm{HSA}]^{\mathrm{a}}$ & 0 & 30 & 70 \\
\hline$[(R)-\mathrm{FBP}] /[\mathrm{HSA}] /[(S)-\mathrm{IBP}]^{\mathrm{b}}$ & 22 & 59 & 19 \\
\hline$[(R)-\mathrm{FBP}] /[\mathrm{HSA}] /[\mathrm{CA}]^{\mathrm{b}}$ & 26 & 61 & 13 \\
\hline$[(R)-\mathrm{FBP}] /[\mathrm{BSA}]$ & 0 & 33 & 67 \\
\hline$[(R)-\mathrm{FBP}] /[\mathrm{BSA}] /[(S)-\mathrm{IBP}]^{\mathrm{b}}$ & 0 & 56 & 44 \\
\hline$[(R)-\mathrm{FBP}] /[\mathrm{BSA}] /[\mathrm{CA}]^{\mathrm{b}}$ & 0 & 50 & 50 \\
\hline
\end{tabular}


Table of Contents

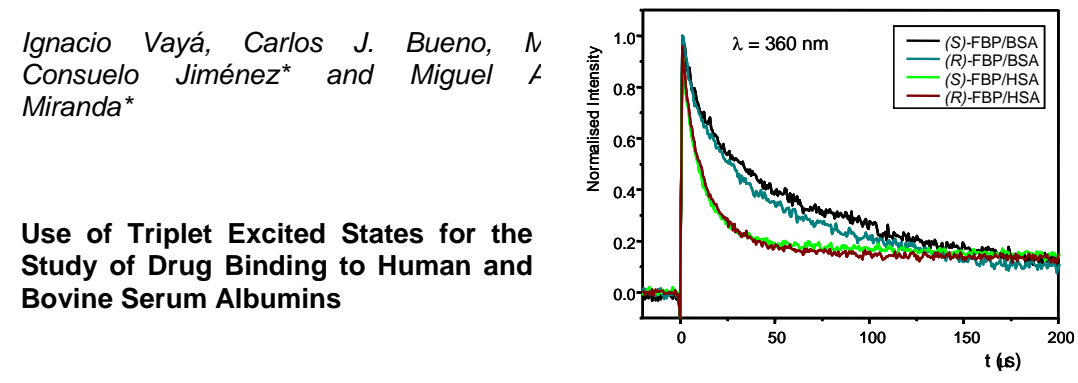

The triplet excited states of (S)- and (R)Flurbiprofen (FBP) have been used as reporters for the microenvironments experienced within the binding sites of serum albumins. Multiexponential fitting of the triplet decays $(\lambda=360 \mathrm{~nm})$ can be satisfactorily correlated with the distribution of the drug among the two protein binding sites and the bulk solution. Both triplet lifetimes and site occupancy are sensitive to the type of serum albumin employed (human vs. bovine). 
Use of Triplet Excited States for the Study of Drug Binding to Human and Bovine

\section{Serum Albumins}

Ignacio Vayá, Carlos J. Bueno, M. Consuelo Jiménez* and Miguel A.

Miranda*

\section{Supporting Information}

- Page S1. This page. First page of the index of supporting information.

- Page S2. Continuation of the index of supporting information.

- Page S3. Figure S1. Laser flash photolysis $\left(\lambda_{\text {exc }}=266 \mathrm{~nm}\right)$ of $(S)$-FBP and $(S)$ FBP/HSA at different molar ratios. Normalised decays monitored at $360 \mathrm{~nm}$ together with their corresponding fittings (in red). The concentration of (S)-FBP was $2.5 \cdot 10^{-5} \mathrm{M}$ in all cases.

- Page S4. Fitting equations corresponding to decays in Figure S1, together with their $r^{2}$ values.

- Page S5. Figure S2. Laser flash photolysis $\left(\lambda_{\text {exc }}=266 \mathrm{~nm}\right)$ of $(R)$-FBP and $(R)-$ FBP/HSA at different molar ratios. Normalised decays monitored at $360 \mathrm{~nm}$ together with their corresponding fittings (in red). The concentration of (R)-FBP was $2.5 \cdot 10^{-5} \mathrm{M}$ in all cases.

- Page S6. Fitting equations corresponding to decays in Figure S2, together with their $\mathrm{r}^{2}$ values.

- Page S7. Figure S3. Laser flash photolysis $\left(\lambda_{\text {exc }}=266 \mathrm{~nm}\right)$ of $(S)$-FBP and $(S)$ FBP/BSA at different molar ratios. Normalised decays monitored at $360 \mathrm{~nm}$ together with their corresponding fittings (in red). The concentration of (S)-FBP was $2.5 \cdot 10^{-5} \mathrm{M}$ in all cases. 
- Page S8. Fitting equations corresponding to decays in Figure S3, together with their $\mathrm{r}^{2}$ values.

- Page S9. Figure S4. Laser flash photolysis $\left(\lambda_{\mathrm{exc}}=266 \mathrm{~nm}\right)$ of $(R)$-FBP and $(R)$ FBP/BSA at different molar ratios. Normalised decays monitored at $360 \mathrm{~nm}$ together with their corresponding fittings (in red). The concentration of (R)-FBP was $2.5 \cdot 10^{-5} \mathrm{M}$ in all cases.

- Page S10. Fitting equations corresponding to decays in Figure S4, together with their $r^{2}$ values.

- Page S11. Figure S5. Laser flash photolysis $\left(\lambda_{\text {exc }}=266 \mathrm{~nm}\right)$ of $(S)$-FBP $\left(2.5 \cdot 10^{-5} \mathrm{M}\right)$ under $\mathrm{N}_{2}$, air and $\mathrm{O}_{2}$. Normalised decays monitored at $360 \mathrm{~nm}$.

- Page S12. Figure S6. Laser flash photolysis $\left(\lambda_{\mathrm{exc}}=266 \mathrm{~nm}\right)$ of equimolar mixtures of (S)-FBP/HSA $\left(2.5 \cdot 10^{-5} \mathrm{M}\right)$ under $\mathrm{N}_{2}$, air and $\mathrm{O}_{2}$. Normalised decays monitored at 360 nm.

- Page S13. Figure S7. Laser flash photolysis $\left(\lambda_{\mathrm{exc}}=266 \mathrm{~nm}\right)$ of equimolar mixtures of (S)-FBP/BSA $\left(2.5 \cdot 10^{-5} \mathrm{M}\right)$ under $\mathrm{N}_{2}$, air and $\mathrm{O}_{2}$. Normalised decays monitored at 360 $\mathrm{nm}$.

- Page S14. Figure S8. Laser flash photolysis $\left(\lambda_{\mathrm{exc}}=266 \mathrm{~nm}\right)$ of equimolar mixtures of (R)-FBP/HSA $\left(2.5 \cdot 10^{-5} \mathrm{M}\right)$ under $\mathrm{N}_{2}$, air and $\mathrm{O}_{2}$. Normalised decays monitored at 360 $\mathrm{nm}$.

- Page S15. Figure S9. Laser flash photolysis $\left(\lambda_{\mathrm{exc}}=266 \mathrm{~nm}\right)$ of equimolar mixtures of (R)-FBP/BSA $\left(2.5 \cdot 10^{-5} \mathrm{M}\right)$ under $\mathrm{N}_{2}$, air and $\mathrm{O}_{2}$. Normalised decays monitored at 360 nm.

- Page S16. Figure S10. Binding plot for (S)-FBP with increasing amounts of HSA.

- Page S17. Figure S11. Binding plot for (S)-FBP with increasing amounts of BSA. 


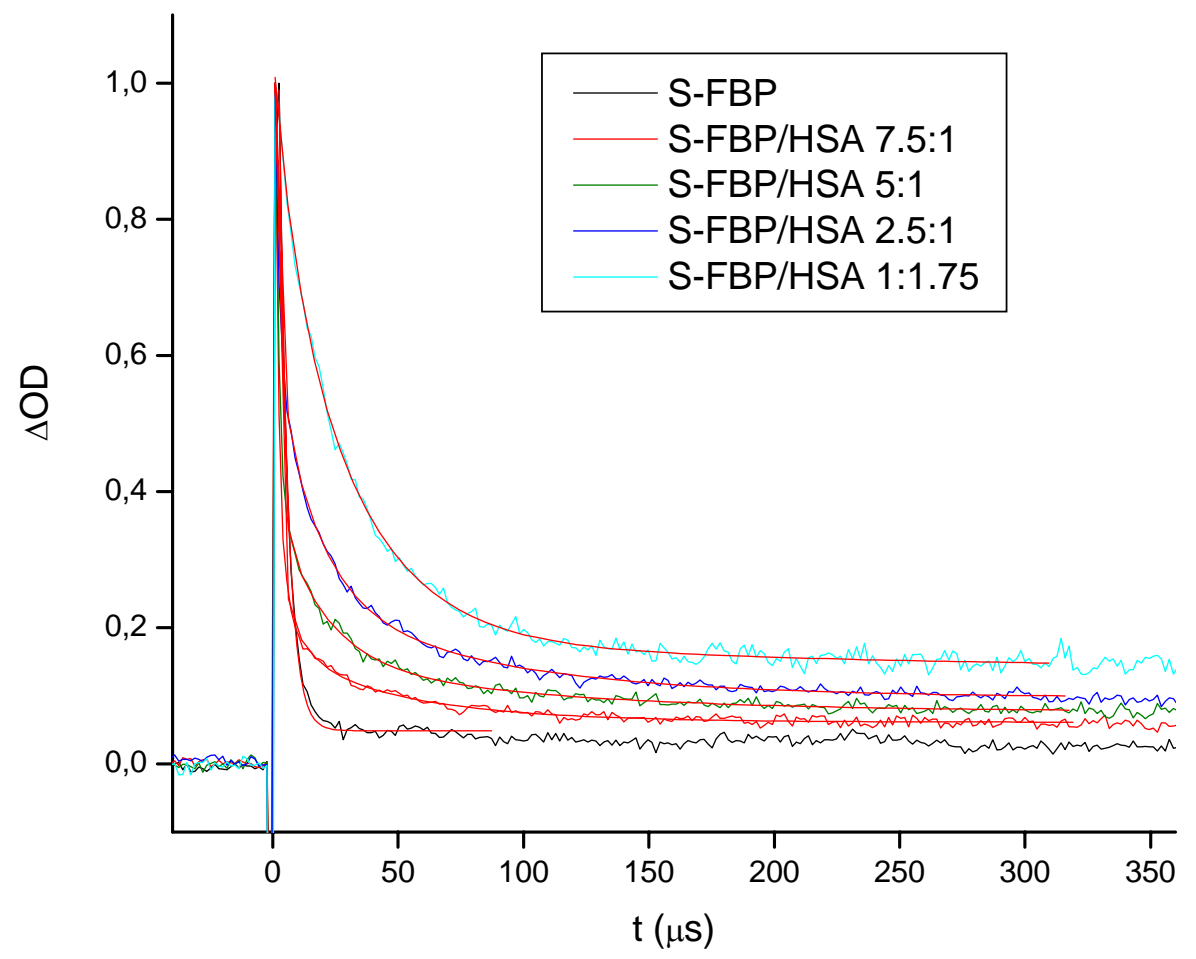

Figure S1 
- Equation fit: $y=y_{0}+A_{\text {free }} \cdot e^{(-x / t}$ SI

$\mathrm{t}_{\text {free }}=1.531 \pm 0.008 \mathrm{~s}$

(S)-FBP

$$
\mathrm{A}_{\text {free }}=1.528 \pm 0.006 ; \mathrm{r}^{2}=0.999
$$

- Equation fit: $\mathrm{y}=\mathrm{y}_{0}+\mathrm{A}_{\mathrm{SI}} \cdot \mathrm{e}^{(-\mathrm{-x} / \mathrm{t}} \mathrm{SI}^{)}+\mathrm{A}_{\mathrm{SII}} \cdot \mathrm{e}^{(-\mathrm{x} / \mathrm{t}} \mathrm{SII}^{)}$

$$
\mathrm{t}_{\mathrm{SI}}=11.2 \pm 1.7 \mathrm{~s} ; \mathrm{t}_{\mathrm{SII}}=35.9 \pm 1.8 \mathrm{~s}
$$

(S)-FBP/HSA 1:1.75

$$
\mathrm{A}_{\mathrm{SI}}=0.29 \pm 0.05 ; \mathrm{A}_{\mathrm{SII}}=0.59 \pm 0.05 ; \mathrm{r}^{2}=0.997
$$

- Equation fit: $y=y_{0}+A_{\text {free }} \cdot e^{(-x / t}$ free $\left.\left.)+A_{S I} \cdot e^{(-x / t}\right)_{S I}+A_{S I I} \cdot e^{(-x / t}{ }_{S I I}\right)$

$$
\mathrm{t}_{\text {free }}=1.531 \pm 0.008 \mathrm{~s} ; \mathrm{t}_{\mathrm{SI}}=11.2 \pm 1.7 \mathrm{~s} ; \mathrm{t}_{\mathrm{SII}}=35.9 \pm 1.8 \mathrm{~s}
$$

(S)-FBP/HSA 7.5:1

$\mathrm{A}_{\text {free }}=1.239 \pm 0.013 ; \mathrm{A}_{\mathrm{SI}}=0.053 \pm 0.008 ; \mathrm{A}_{\mathrm{SII}}=0.140 \pm 0.004 ; \mathrm{r}^{2}=0.994$

\section{(S)-FBP/HSA 5:1}

$$
\mathrm{A}_{\text {free }}=1.02 \pm 0.02 ; \mathrm{A}_{\mathrm{SI}}=0.09 \pm 0.01 ; \mathrm{A}_{\mathrm{SII}}=0.221 \pm 0.005 ; \mathrm{r}^{2}=0.993
$$

\section{(S)-FBP/HSA 2.5:1}

$\mathrm{A}_{\text {free }}=0.69 \pm 0.02 ; \mathrm{A}_{\mathrm{SI}}=0.143 \pm 0.013 ; \mathrm{A}_{\mathrm{SII}}=0.350 \pm 0.007 ; \mathrm{r}^{2}=0.992$ 


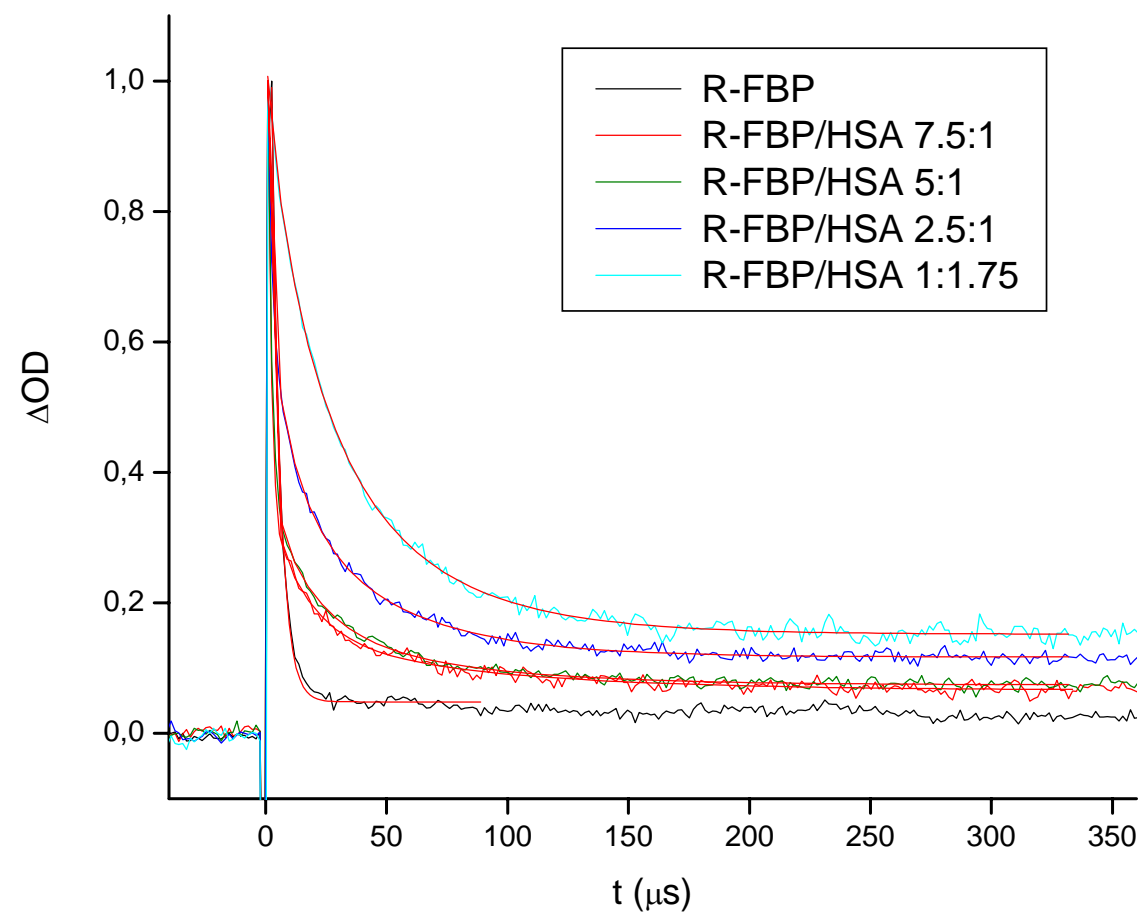

Figure S2 
- Equation fit: $y=y_{0}+A_{\text {free }} \cdot e^{(-x / t}$ SI

$$
\mathrm{t}_{\text {free }}=1.503 \pm 0.005 \mathrm{~s}
$$

(R)-FBP

$$
\mathrm{A}_{\text {free }}=1.524 \pm 0.003 ; \mathrm{r}^{2}=0.999
$$

- Equation fit: $\mathrm{y}=\mathrm{y}_{0}+\mathrm{A}_{\mathrm{SI}} \cdot \mathrm{e}^{(-\mathrm{-x} / \mathrm{t}} \mathrm{SI}^{)}+\mathrm{A}_{\mathrm{SII}} \cdot \mathrm{e}^{(-\mathrm{x} / \mathrm{t}} \mathrm{SII}^{)}$

$$
\mathrm{t}_{\mathrm{SI}}=10.2 \pm 1.3 \mathrm{~s} ; \mathrm{t}_{\mathrm{SII}}=39.0 \pm 1.5 \mathrm{~s}
$$

(R)-FBP/HSA 1:1.75

$$
\mathrm{A}_{\mathrm{SI}}=0.26 \pm 0.03 ; \mathrm{A}_{\mathrm{SII}}=0.62 \pm 0.03 ; \mathrm{r}^{2}=0.998
$$

- Equation fit: $y=y_{0}+A_{\text {free }} \cdot e^{(-x / t}$ free $\left.\left.)+A_{S I} \cdot e^{(-x / t}\right)_{S I}+A_{S I I} \cdot e^{(-x / t}{ }_{S I I}\right)$

$$
\mathrm{t}_{\text {free }}=1.503 \pm 0.005 \mathrm{~s} ; \mathrm{t}_{\mathrm{SI}}=10.2 \pm 1.3 \mathrm{~s} ; \mathrm{t}_{\mathrm{SII}}=39.0 \pm 1.5 \mathrm{~s}
$$

(R)-FBP/HSA 7.5:1

$\mathrm{A}_{\text {free }}=1.10 \pm 0.02 ; \mathrm{A}_{\mathrm{SI}}=0.082 \pm 0.011 ; \mathrm{A}_{\mathrm{SII}}=0.185 \pm 0.005 ; \mathrm{r}^{2}=0.991$

\section{(R)-FBP/HSA 5:1}

$\mathrm{A}_{\text {free }}=1.023 \pm 0.014 ; \mathrm{A}_{\mathrm{SI}}=0.111 \pm 0.008 ; \mathrm{A}_{\mathrm{SII}}=0.201 \pm 0.004 ; \mathrm{r}^{2}=0.995$

\section{(R)-FBP/HSA 2.5:1}

$\mathrm{A}_{\text {free }}=0.61 \pm 0.02 ; \mathrm{A}_{\mathrm{SI}}=0.235 \pm 0.009 ; \mathrm{A}_{\text {SII }}=0.305 \pm 0.004 ; \mathrm{r}^{2}=0.996$ 


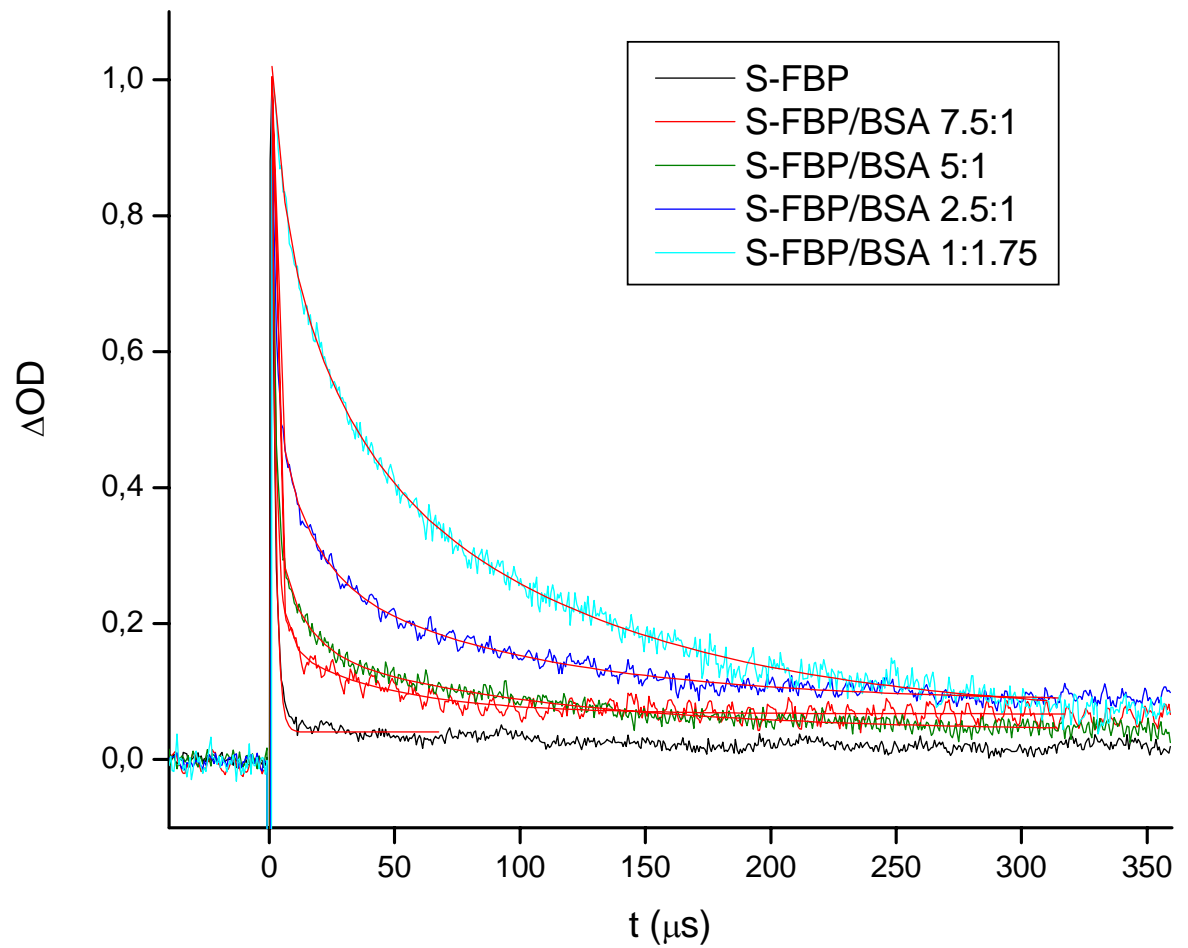

Figure S3 
- Equation fit: $y=y_{0}+A_{\text {free }} \cdot e^{(-x / t}$ SI

$$
\mathrm{t}_{\text {free }}=1.529 \pm 0.004 \mathrm{~s}
$$

(S)-FBP

$$
\mathrm{A}_{\text {free }}=1.517 \pm 0.003 ; \mathrm{r}^{2}=0.999
$$

- Equation fit: $\left.\mathrm{y}=\mathrm{y}_{0}+\mathrm{A}_{\mathrm{SI}} \cdot \mathrm{e}^{(-\mathrm{-x} / \mathrm{t}} \mathrm{SI}\right)+\mathrm{A}_{\mathrm{SII}} \cdot \mathrm{e}^{(-\mathrm{x} / \mathrm{t}} \mathrm{SII}^{)}$

$$
\mathrm{t}_{\mathrm{SI}}=10.8 \pm 0.6 \mathrm{~s} ; \mathrm{t}_{\mathrm{SII}}=86.5 \pm 2.2 \mathrm{~s}
$$

(S)-FBP/BSA 1:1.75

$$
\mathrm{A}_{\mathrm{SI}}=0.37 \pm 0.01 ; \mathrm{A}_{\mathrm{SII}}=0.581 \pm 0.008 ; \mathrm{r}^{2}=0.994
$$

- Equation fit: $y=y_{0}+A_{\text {free }} \cdot e^{(-x / t}$ free $\left.\left.)+A_{S I} \cdot e^{(-x / t}\right)_{S I}+A_{S I I} \cdot e^{(-x / t}{ }_{S I I}\right)$

$$
\mathrm{t}_{\text {free }}=1.529 \pm 0.004 \mathrm{~s} ; \mathrm{t}_{\mathrm{SI}}=10.8 \pm 0.6 \mathrm{~s} ; \mathrm{t}_{\mathrm{SII}}=86.5 \pm 2.2 \mathrm{~s}
$$

(S)-FBP/BSA 7.5:1

$\mathrm{A}_{\text {free }}=1.44 \pm 0.02 ; \mathrm{A}_{\mathrm{SI}}=0.138 \pm 0.007 ; \mathrm{A}_{\text {SII }}=0.063 \pm 0.003 ; \mathrm{r}^{2}=0.989$

\section{(S)-FBP/BSA 5:1}

$\mathrm{A}_{\text {free }}=1.21 \pm 0.02 ; \mathrm{A}_{\mathrm{SI}}=0.158 \pm 0.005 ; \mathrm{A}_{\mathrm{SII}}=0.137 \pm 0.002 ; \mathrm{r}^{2}=0.991$

\section{(S)-FBP/BSA 2.5:1}

$\mathrm{A}_{\text {free }}=0.71 \pm 0.02 ; \mathrm{A}_{\mathrm{SI}}=0.281 \pm 0.006 ; \mathrm{A}_{\mathrm{SII}}=0.391 \pm 0.002 ; \mathrm{r}^{2}=0.991$ 


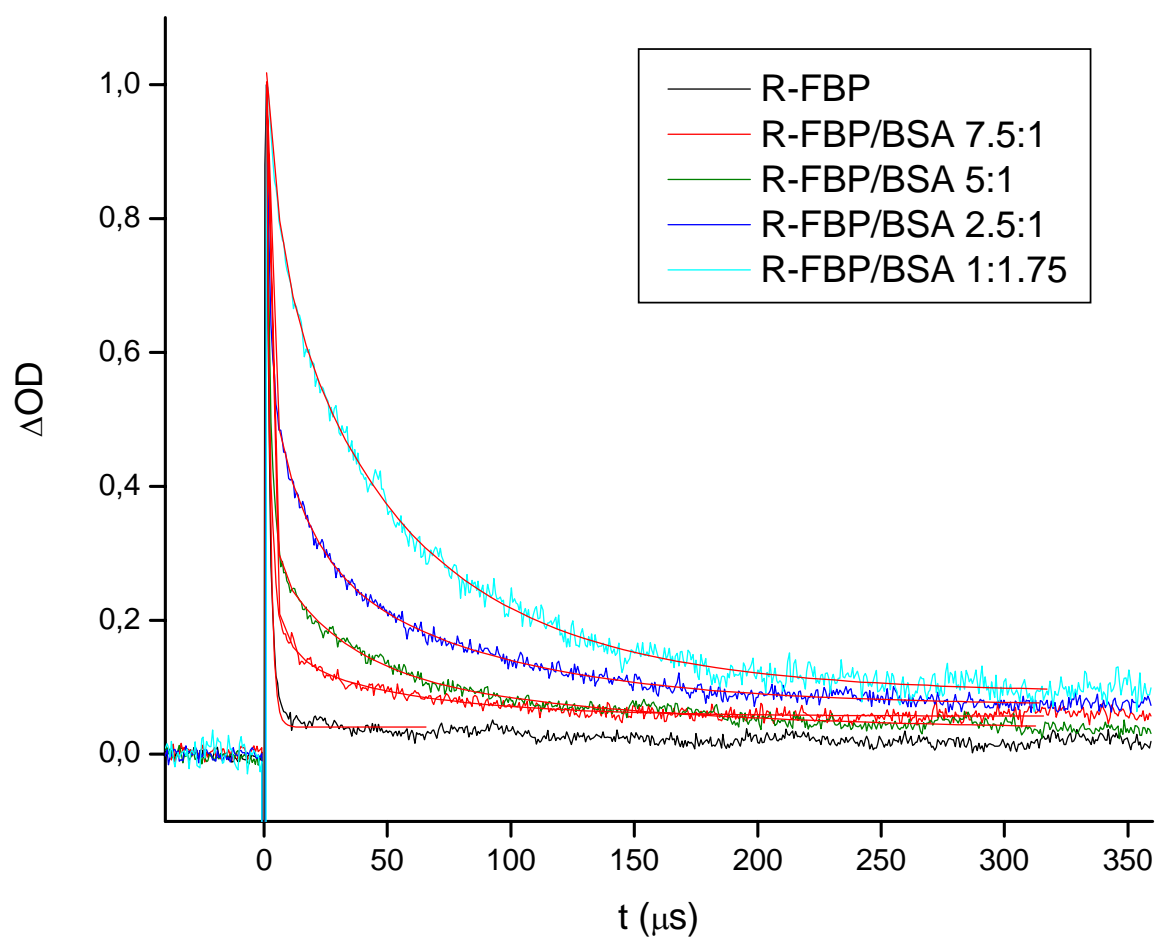

Figure S4 
- Equation fit: $y=y_{0}+A_{\text {free }} \cdot e^{(-x / t}$ SI

$$
\mathrm{t}_{\text {free }}=1.514 \pm 0.002 \mathrm{~s}
$$

(R)-FBP

$$
\mathrm{A}_{\text {free }}=1.532 \pm 0.004 ; \mathrm{r}^{2}=0.999
$$

- Equation fit: $\left.\mathrm{y}=\mathrm{y}_{0}+\mathrm{A}_{\mathrm{SI}} \cdot \mathrm{e}^{(-\mathrm{-x} / \mathrm{t}} \mathrm{SI}\right)+\mathrm{A}_{\mathrm{SII}} \cdot \mathrm{e}^{(-\mathrm{x} / \mathrm{t}} \mathrm{SII}^{)}$

$$
\mathrm{t}_{\mathrm{SI}}=6.6 \pm 0.4 \mathrm{~s} ; \mathrm{t}_{\mathrm{SII}}=58.6 \pm 0.9 \mathrm{~s}
$$

(R)-FBP/BSA 1:1.75

$$
\mathrm{A}_{\mathrm{SI}}=0.318 \pm 0.011 ; \mathrm{A}_{\mathrm{SII}}=0.644 \pm 0.007 ; \mathrm{r}^{2}=0.995
$$

- Equation fit: $y=y_{0}+A_{\text {free }} \cdot e^{(-x / t}$ free $\left.\left.)+A_{S I} \cdot e^{(-x / t}\right)_{S I}+A_{S I I} \cdot e^{(-x / t}{ }_{S I I}\right)$

$$
\mathrm{t}_{\text {free }}=1.514 \pm 0.002 \mathrm{~s} ; \mathrm{t}_{\mathrm{SI}}=6.6 \pm 0.4 \mathrm{~s} ; \mathrm{t}_{\mathrm{SII}}=58.6 \pm 0.9 \mathrm{~s}
$$

(R)-FBP/BSA 7.5:1

$\mathrm{A}_{\text {free }}=1.39 \pm 0.02 ; \mathrm{A}_{\mathrm{SI}}=0.121 \pm 0.007 ; \mathrm{A}_{\mathrm{SII}}=0.092 \pm 0.002 ; \mathrm{r}^{2}=0.991$ (R)-FBP/BSA 5:1

$\mathrm{A}_{\text {free }}=1.21 \pm 0.02 ; \mathrm{A}_{\mathrm{SI}}=0.124 \pm 0.008 ; \mathrm{A}_{\mathrm{SII}}=0.214 \pm 0.002 ; \mathrm{r}^{2}=0.993$ (R)-FBP/BSA 2.5:1

$\mathrm{A}_{\text {free }}=0.68 \pm 0.02 ; \mathrm{A}_{\mathrm{SI}}=0.264 \pm 0.008 ; \mathrm{A}_{\mathrm{SII}}=0.329 \pm 0.002 ; \mathrm{r}^{2}=0.994$ 


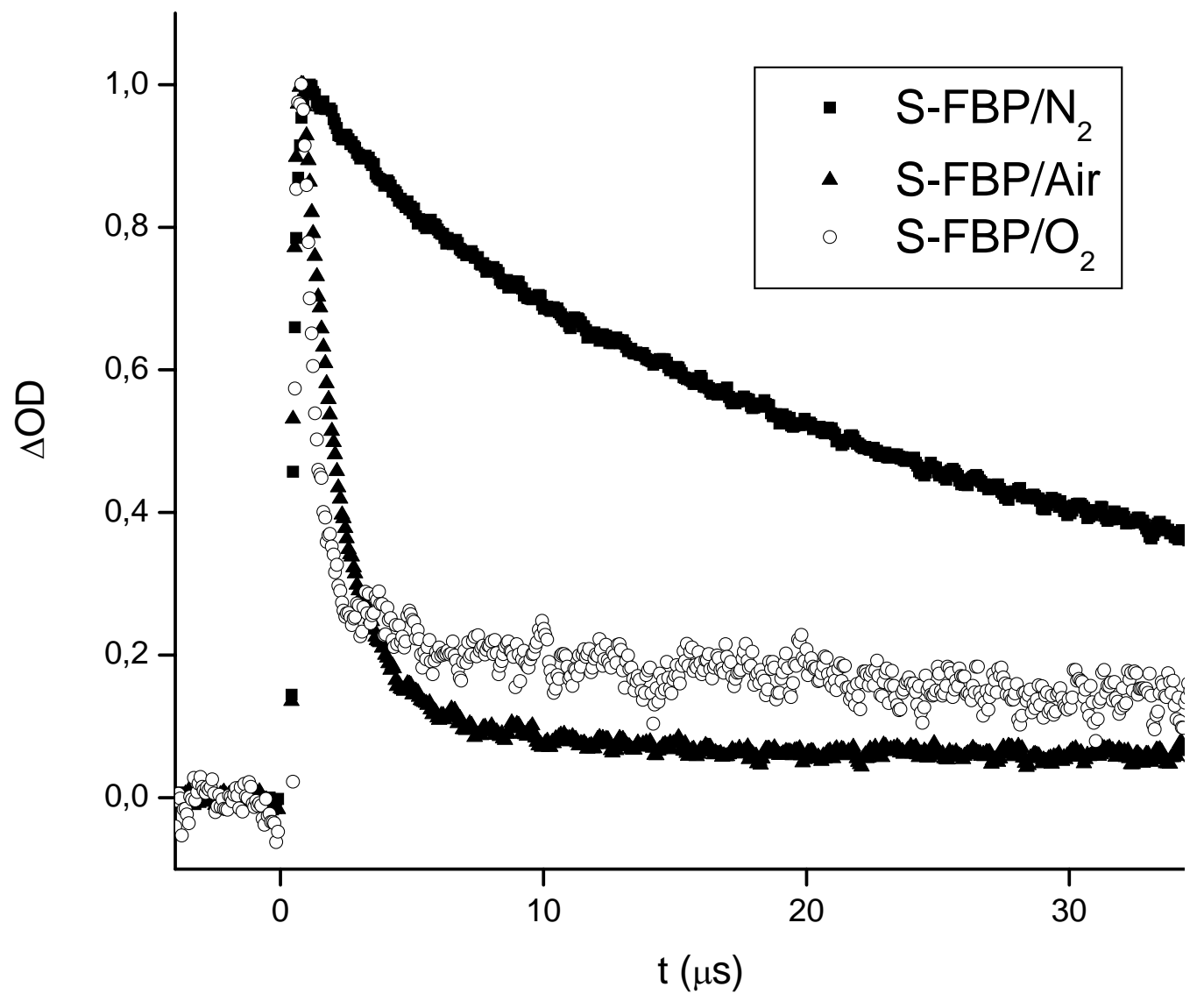

Figure S5 


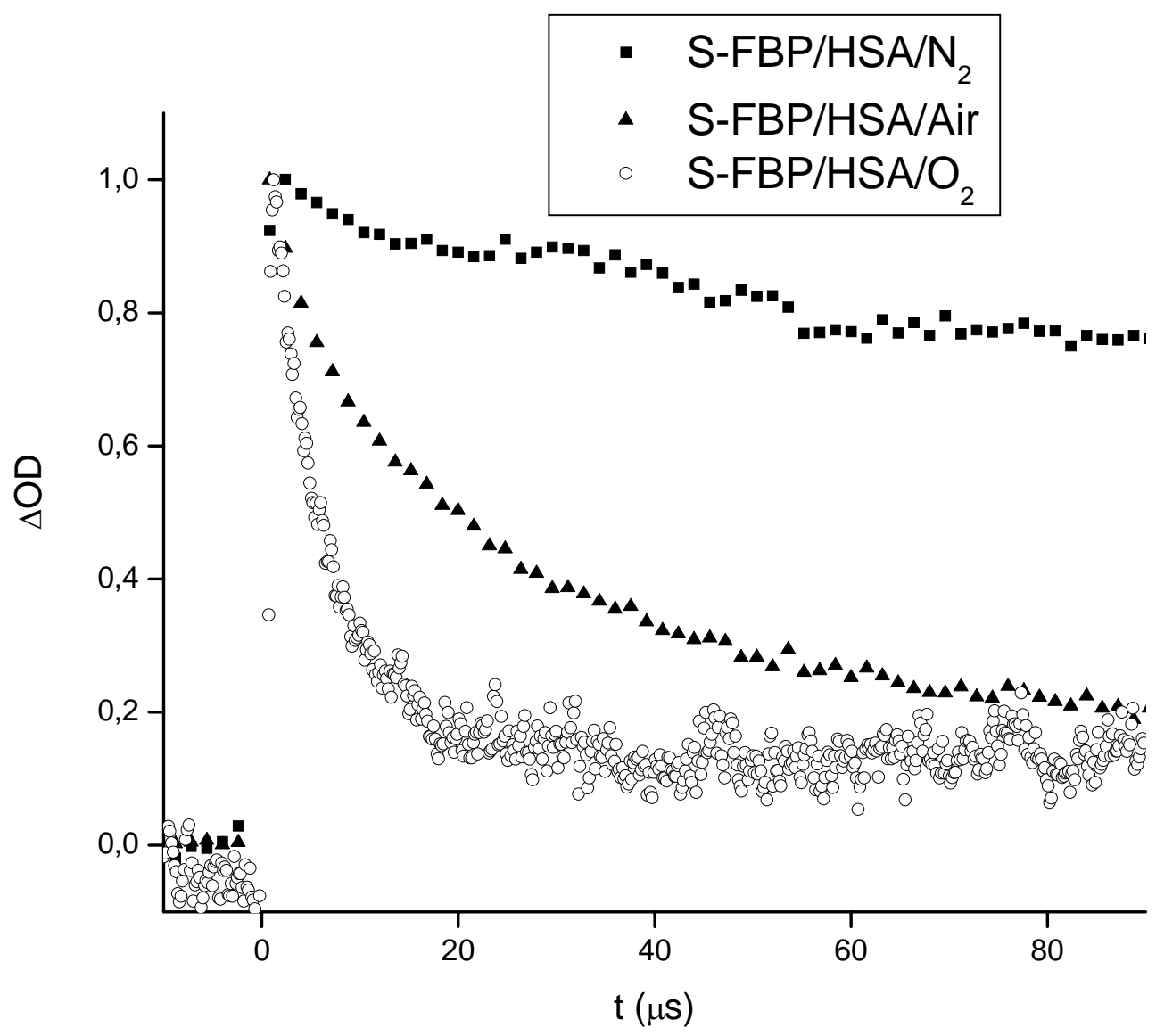

Figure S6 


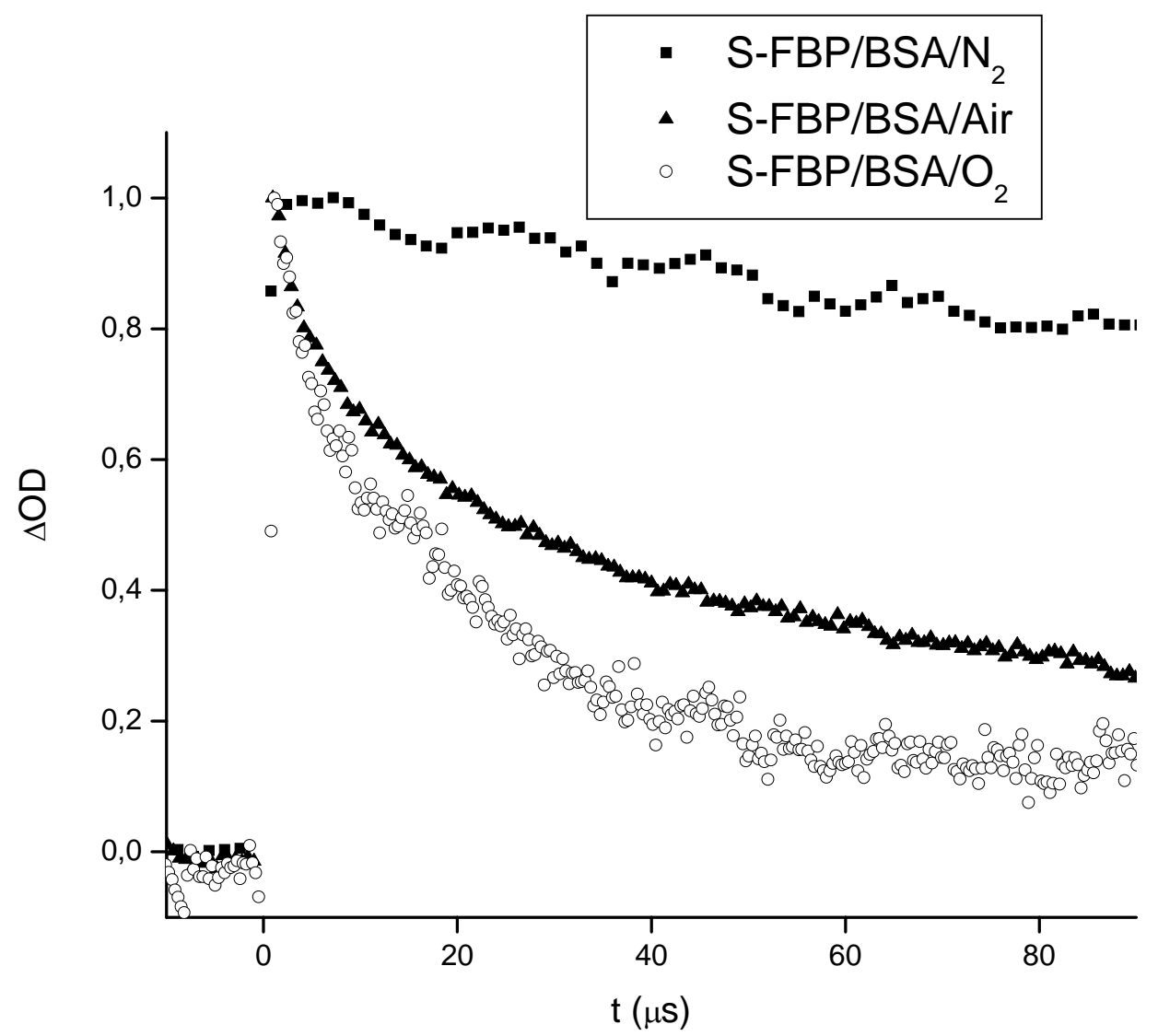

Figure S7 


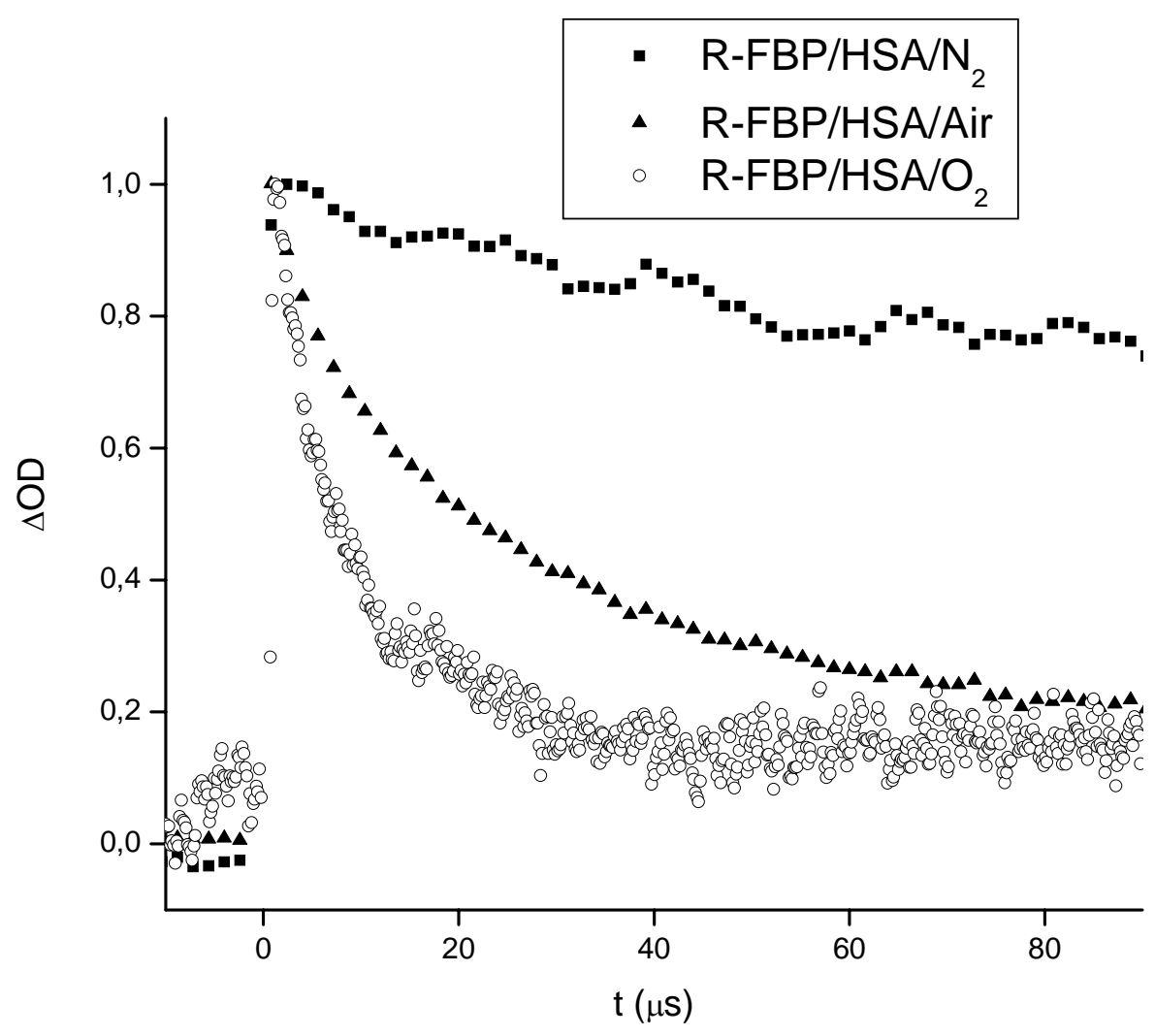

Figure S8 


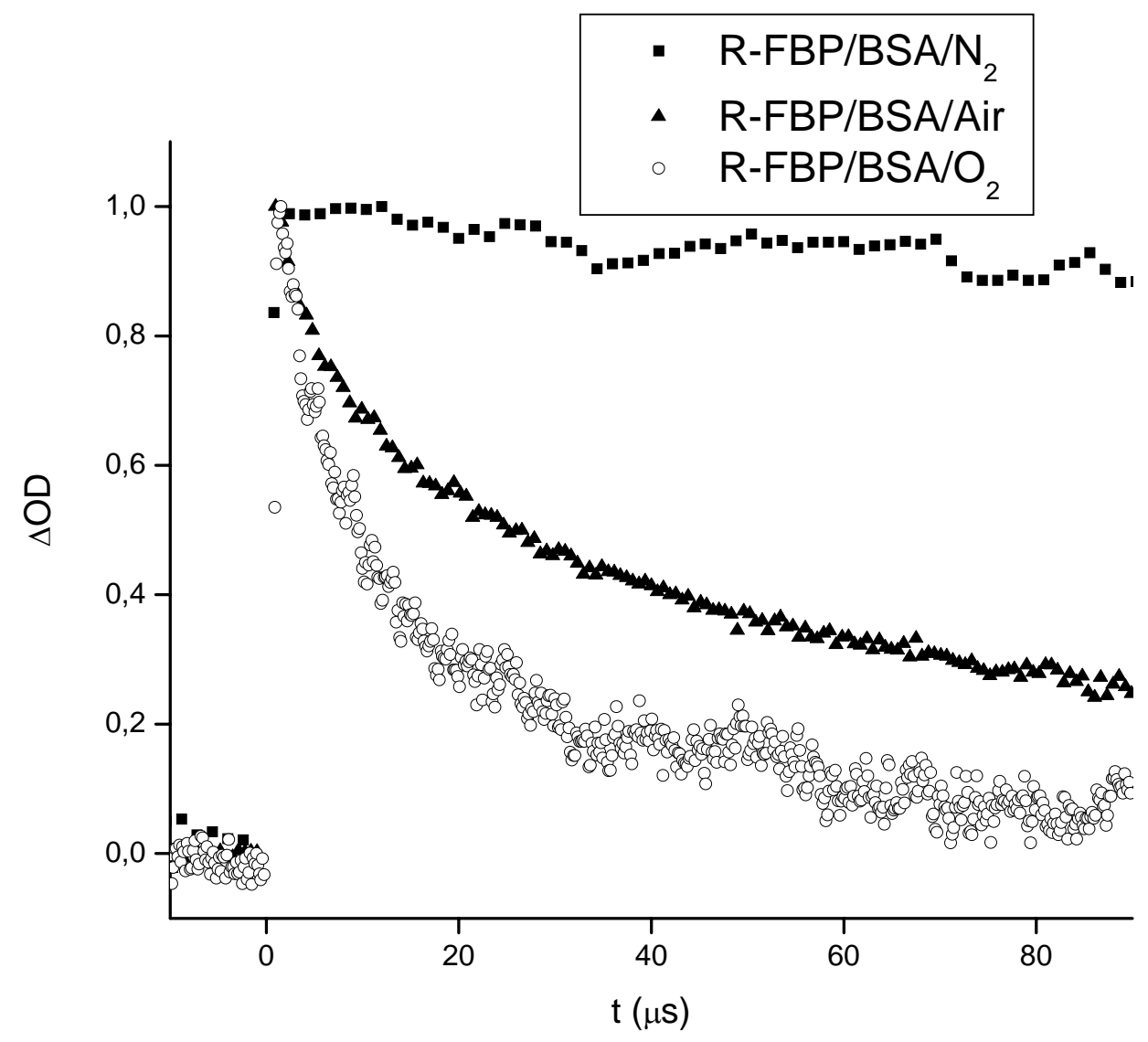

Figure S9 


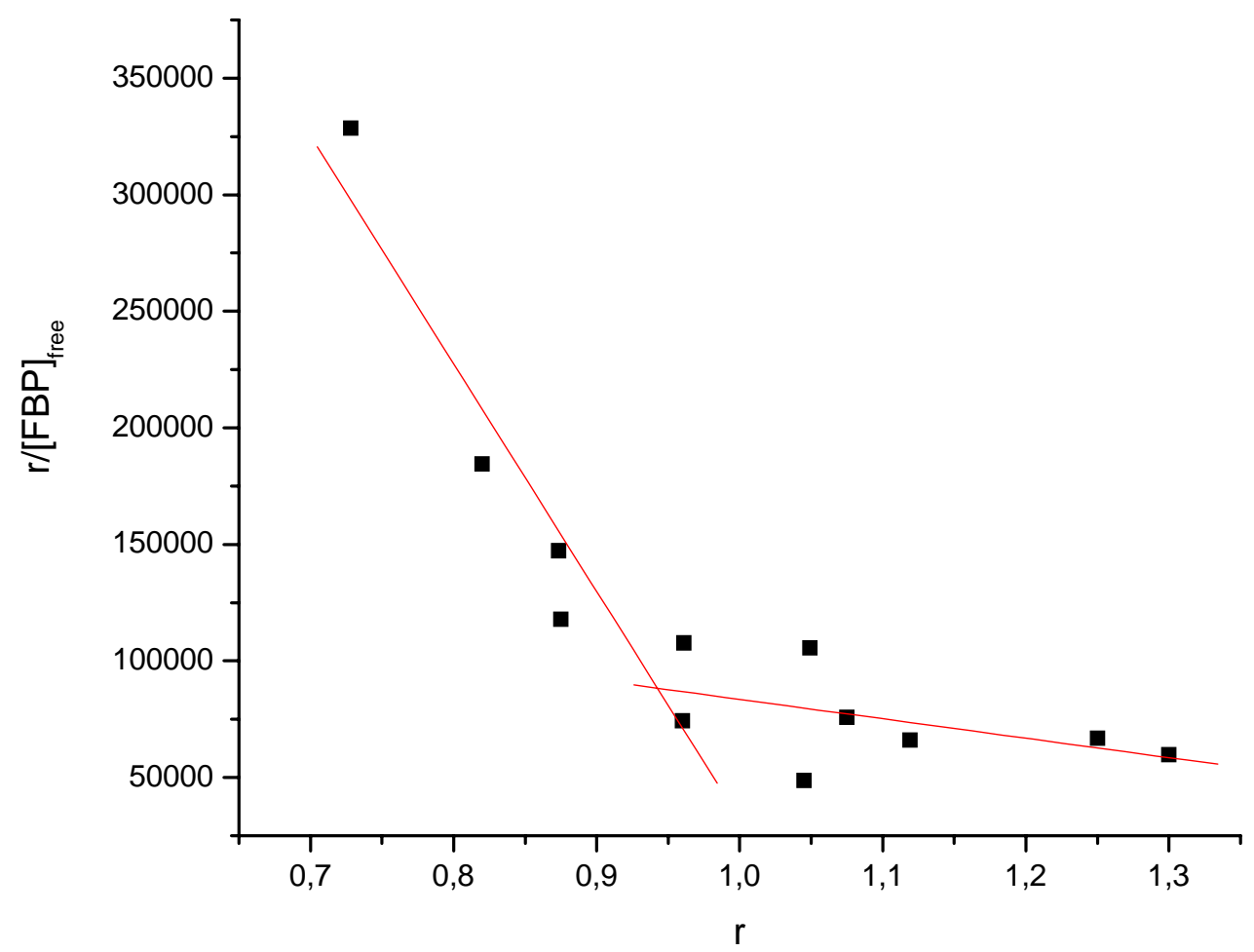

Figure S10 


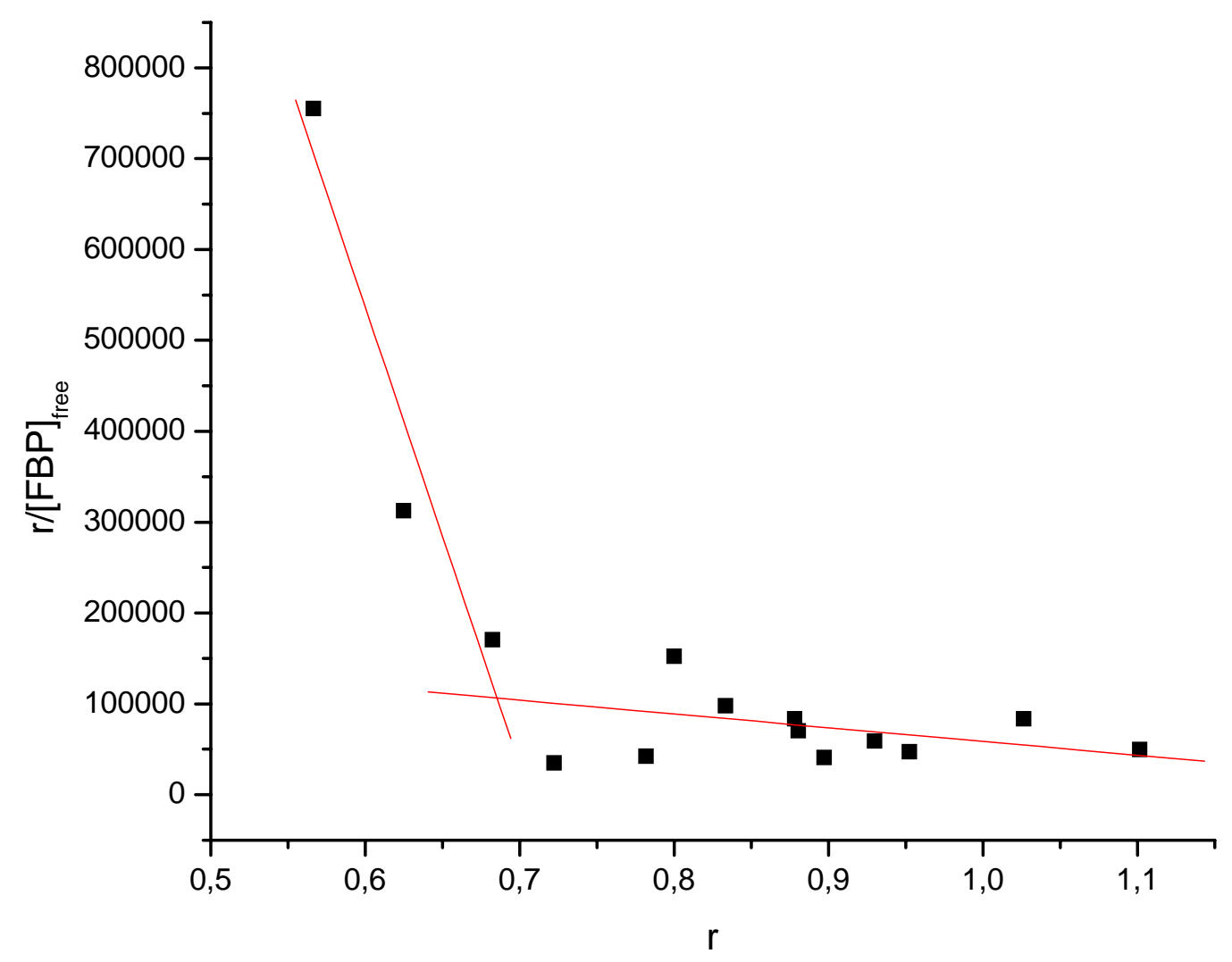

Figure S11 